\title{
Mutation of Aryl Binding-Pocket Residues Results in an Unexpected Activity Switch in an Oryza sativa
}

\section{Tyrosine Aminomutase}

\author{
Tyler Walter ${ }^{\dagger}$, Devinda Wijewardena ${ }^{\dagger}$, Kevin D. Walker ${ }^{\dagger *} *$
}

${ }^{\dagger}$ Department of Chemistry, Michigan State University, East Lansing, MI 48824, USA.

${ }^{\ddagger}$ Department of Biochemistry and Molecular Biology, Michigan State University, East Lansing, MI 48824, USA.

Supporting Information 
Index

Page 4S. 


\section{Instrumentation}

Page 4S. Synthesis of $4{ }^{\prime}-O, 3-N$-di(ethoxycarbonyl) $\beta$-Tyrosine Ethyl Ester and 4 '- $O$ Ethoxycarbonyl 4'-Hydroxycinnamate Ethyl Ester

Page 5S. Synthesis of 3-N-(Ethoxycarbonyl) $\beta$-Phenylalanine Methyl Ester and (E)Cinnamate Methyl Ester Derivatives

Page 6S. Figure S1. SDS-PAGE gel of Y125C-OsTAM after Coomassie blue staining. Purity $(61 \%)$ estimated by a Kodak Gel Logic 100 Imaging System.

Page 7S. $\quad$ Figure S2. SDS-PAGE gel of N446K-OsTAM after Coomassie blue staining. Purity (85\%) estimated by a Kodak Gel Logic 100 Imaging System.

Page 8S. Figure S3. SDS-PAGE gel of Y125C/N446K-OsTAM after Coomassie blue staining. Purity (65\%) estimated by a Kodak Gel Logic 100 Imaging System.

Page 9S. Figure S4. EI-MS of 4'-O,3- $N$-di(ethoxycarbonyl) ethyl ester derivative of authentic (3R)- $\beta$-tyrosine.

Page 10S. Figure S5. EI-MS of 4'-O-ethoxycarbonyl ethyl ester derivative of authentic 4'hydroxycinnamic acid.

Page 11S. Figure S6. EI-MS of 3- $N$-ethoxycarbonyl methyl ester of authentic $(3 R)-\beta$ phenylalanine.

Page 12S. Figure S7. EI-MS of methyl ester of authentic $(E)$-cinnamate.

Page 13S. Figure S8. EI-MS of 4'-O,3- $N$-di(ethoxycarbonyl) ethyl ester derivative biosynthesized from $(2 S)$ - $\alpha$-tyrosine by Y125C-OsTAM.

Page 14S. Figure S9. EI-MS of 4'-O,3- $N$-di(ethoxycarbonyl) ethyl ester derivative biosynthesized from $(2 S)-\alpha$-tyrosine by N446-OsTAM.

Page 15S. Figure S10. EI-MS of 4'-O-ethoxycarbonyl ethyl ester derivative of 4'hydroxycinnamic acid biosynthesized from $(2 S)$ - $\alpha$-tyrosine by Y125C-OsTAM.

Page 16S. Figure S11. EI-MS of 4'- $O$-ethoxycarbonyl ethyl ester derivative of 4'hydroxycinnamic acid biosynthesized from $(2 S)$ - $\alpha$-tyrosine by N446K-OsTAM.

Page 16S. Figure S12. Partial extracted ion chromatograms for the 4'-O,3-Ndi(ethoxycarbonyl) ethyl ester derivative of $\beta$-tyrosine $(\mathrm{m} / \mathrm{z}, 280)$ produced over 18 h by (A) Y125C-OsTAM and (B) N446K-OsTAM and 4'-O-ethoxycarbonyl derivative of $p$-coumarate $(\mathrm{m} / \mathrm{z} 147)$ produced over $18 \mathrm{~h}$ by $(\mathrm{C}) \mathrm{Y} 125 \mathrm{C}-O s \mathrm{TAM}$ and (D) N446K-OsTAM. Peaks of interest indicated by arrows.

Page 17S. Figure S13. EI-MS of 3- $N$-ethoxycarbonyl methyl ester of $\beta$-tyrosine biosynthesized from $(2 S)-\alpha$-phenylalanine by Y125C-OsTAM.

Page 18S. Figure S14. EI-MS of 3 - $N$-ethoxycarbonyl methyl ester of $\beta$-tyrosine biosynthesized from $(2 S)$ - $\alpha$-phenylalanine by N446K-OsTAM.

Page 18S. Figure S15. EI-MS of 3- $N$-ethoxycarbonyl methyl ester of $\beta$-tyrosine biosynthesized from $(2 S)$ - $\alpha$-phenylalanine by Y125C/N446K-OsTAM.

Page 19S. Figure S16. EI-MS of methyl ester of $(E)$-cinnamate biosynthesized from $(2 S)-\alpha-$ phenylalanine by Y125C-OsTAM.

Page 20S. Figure S17. EI-MS of methyl ester of $(E)$-cinnamate biosynthesized from $(2 S)$ - $\alpha$ phenylalanine by N446K-OsTAM.

Page 20S. Figure S18. EI-MS of methyl ester of $(E)$-cinnamate biosynthesized from $(2 S)$ - $\alpha$ phenylalanine by Y125C/N446K-OsTAM.

Page 21S. Figure S19. Partial extracted ion chromatograms for the 3- $N$-ethoxycarbonyl methyl ester derivative of $\beta$-phenylalanine $(\mathrm{m} / \mathrm{z} 178)$ produced over $18 \mathrm{~h}$ by (A) Y125C-OsTAM and (B) N446K-OsTAM and the methyl ester of (E)-cinnamate 
$(\mathrm{m} / \mathrm{z}$ 131) produced over $18 \mathrm{~h}$ by (C) Y125C-OsTAM and (D) N446K-OsTAM. Peaks of interest indicated by arrows.

Page 21S. Figure S20. Partial ion extracted chromatograms for (A) the 4'-O,3-Ndi(ethoxycarbonyl) ethyl ester derivative of $\beta$-phenylalanine $(\mathrm{m} / \mathrm{z} 280)$ and the 4 '$O$-ethoxycarbonyl ethyl ester derivative of $p$-coumarate $(\mathrm{m} / \mathrm{z} 147)$, and (B) the 3$\mathrm{N}$-ethoxycarbonyl methyl ester derivative of $\beta$-phenylalanine $(\mathrm{m} / \mathrm{z}, 178)$ and methyl ester of $(E)$-cinnamate $(\mathrm{m} / \mathrm{z}, 131)$ produced over $18 \mathrm{~h}$ for $\mathrm{Y} 125 \mathrm{C} / \mathrm{N} 446 \mathrm{~K}$ OsTAM. Peaks of interest indicated by arrows.

Page 22S. Figure S21. Non-linear regression plot $\left(v=k_{\text {cat }}^{\text {total }}[\mathrm{E}]_{\mathrm{o}}[\mathrm{S}] /\left(K_{\mathrm{M}}+[\mathrm{S}]\right)\right)$ for total product $(\beta$ tyrosine + coumarate) biosynthesized by Y125C-OsTAM $(\boldsymbol{\nabla})$. The steady state productions of $\beta$-tyrosine $(\bullet)$ and coumarate (o) are plotted separately. $k_{\text {cat }}^{\text {total }}=k_{\text {cat }}^{\beta-T y r}+$ $k_{\text {cat }}^{\text {Coum }} . K_{\mathrm{M}}=0.51 \mathrm{mM}, k_{\text {cat }}^{\beta-\mathrm{Tyr}}=5.3 \times 10^{-5} \mathrm{~s}^{-1}, k_{\text {cat }}^{\text {Coum }}=1.8 \times 10^{-4} \mathrm{~s}^{-1}$.

Page 22S. Figure S22. Non-linear regression plot $\left(v=k_{\text {cat }}^{\text {total }}[\mathrm{E}]_{\mathrm{o}}[\mathrm{S}] /\left(K_{\mathrm{M}}+[\mathrm{S}]\right)\right)$ for a total product $(\beta-$ tyrosine + coumarate) biosynthesized by N446K-OsTAM $(\boldsymbol{\nabla})$. The steady state productions of $\beta$-tyrosine $(\bullet)$ and coumarate $(0)$ are plotted separately. $k_{\text {cat }}^{\text {total }}=k_{\text {cat }}^{\beta-T y r}+$ $k_{\text {cat }}^{\text {Coum }} . K_{\mathrm{M}}=0.64 \mathrm{mM}, k_{\text {cat }}^{\beta-\mathrm{Tyr}}=2.1 \times 10^{-6} \mathrm{~s}^{-1}, k_{\text {cat }}^{\text {Coum }}=8.6 \times 10^{-5} \mathrm{~s}^{-1}$.

Page 23S. Figure S23. Non-linear regression plot $\left(v=k_{\text {cat }}^{\text {total }}[\mathrm{E}]_{\mathrm{o}}[\mathrm{S}] /\left(K_{\mathrm{M}}+[\mathrm{S}]\right)\right)$ for a total product $(\beta$ phenylalanine + cinnamate) biosynthesized by Y125C-OSTAM $(\boldsymbol{\nabla})$. The steady state productions of $\beta$-phenylalanine $(\bullet)$ and cinnamate $(0)$ are plotted separately. $k_{\text {cat }}^{\text {total }}=$ $k_{\text {cat }}^{\beta-P h e}+k_{\text {cat }}^{\text {Cinn }} . K_{\mathrm{M}}=1.0 \mathrm{mM}, k_{\text {cat }}^{\beta-P h e}=3.5 \times 10^{-5} \mathrm{~s}^{-1}, k_{\text {cat }}^{\text {Cinn }}=1.2 \times 10^{-3} \mathrm{~s}^{-1}$.

Page 23S. Figure S24. Non-linear regression plot $\left(v=k_{\text {cat }}^{\text {total }}[\mathrm{E}]_{\mathrm{o}}[\mathrm{S}] /\left(K_{\mathrm{M}}+[\mathrm{S}]\right)\right)$ for a total product $(\beta$ phenylalanine + cinnamate) biosynthesized by N446K-OsTAM ( $\boldsymbol{\nabla})$. The steady state productions of $\beta$-phenylalanine $(\bullet)$ and cinnamate $(0)$ are plotted separately. $k_{\text {cat }}^{\text {total }}=$ $k_{\text {cat }}^{\beta-P h e}+k_{\text {cat }}^{\text {Cinn }} \cdot K_{\mathrm{M}}=0.72 \mathrm{mM}, k_{\text {cat }}^{\beta-P h e}=8.0 \times 10^{-5} \mathrm{~s}^{-1}, k_{\text {cat }}^{\text {Cinn }}=1.3 \times 10^{-3} \mathrm{~s}^{-1}$.

Page 24S. Figure S25. Non-linear regression plot $\left(v=k_{\text {cat }}^{\text {total }}[\mathrm{E}]_{\mathrm{o}}[\mathrm{S}] /\left(K_{\mathrm{M}}+[\mathrm{S}]\right)\right)$ for a total product $(\beta$ phenylalanine + cinnamate) biosynthesized by Y125C/N446K-OsTAM ( $\mathbf{\nabla})$. The steady state productions of $\beta$-phenylalanine $(\bullet)$ and cinnamate $(0)$ are plotted separately. $k_{\text {cat }}^{\text {total }}$ $=k_{\text {cat }}^{\beta-\text { Phe }}+k_{\text {cat }}^{\text {Cinn }} . K_{\mathrm{M}}=0.49 \mathrm{mM}, k_{\text {cat }}^{\beta-P h e}=5.2 \times 10^{-5} \mathrm{~s}^{-1}, k_{\text {cat }}^{\text {Cinn }}=2.0 \times 10^{-3} \mathrm{~s}^{-1}$.

Page 25S. Figure S26. Linear regression plot $\left(1 / v=\left(K_{\mathrm{M}} /[\mathrm{S}] \mathrm{V}_{\max }\right)+1 / \mathrm{V}_{\max }\right)$ for cinnamate biosynthesized by $O s$ TAM. $k_{\text {cat }}^{\text {Cinn }}=3.6 \times 10^{-4} \mathrm{~s}^{-1}$. 


\section{Instrumentation}

GC-MS analysis was performed on an Agilent $6890 \mathrm{~N}$ gas chromatograph equipped with a capillary GC column ( $30 \mathrm{~m} \times 0.25 \mathrm{~mm} \times 0.25 \mathrm{uM}$; HP-5MS; J \& W Scientific) with He as the carrier gas (flow rate, $1 \mathrm{~mL} / \mathrm{min}$ ). The injector port (at $250{ }^{\circ} \mathrm{C}$ ) was set to splitless injection mode. A 1-uL aliquot of each sample was injected using an Agilent 7683 auto-sampler (Agilent, Atlanta, GA). The column temperature was increased from $200-220{ }^{\circ} \mathrm{C}$ at $8{ }^{\circ} \mathrm{C} / \mathrm{min}$ with a 13 min hold, then increased by $50{ }^{\circ} \mathrm{C} / \mathrm{min}$ to $250{ }^{\circ} \mathrm{C}$, and returned to $200{ }^{\circ} \mathrm{C}$ over $5 \mathrm{~min}$, with a 5 min hold for tyrosine and para-coumarate detection; the column temperature was increased from $50-110{ }^{\circ} \mathrm{C}$ at $30^{\circ} \mathrm{C} / \mathrm{min}$ then increased by $10{ }^{\circ} \mathrm{C} / \mathrm{min}$ to $250{ }^{\circ} \mathrm{C}$, and returned to $50{ }^{\circ} \mathrm{C}$ over 5 min, with a 5 min hold for phenylalanine and cinnamate detection. The gas chromatograph was coupled to a mass selective detector (Agilent, 5973 inert) operated in electron impact mode (70 $\mathrm{eV}$ ionization voltage). All spectra were recorded in the mass range of $50-400 \mathrm{~m} / \mathrm{z}$ to analyze amino acid and acrylate derivatives.

\section{Synthesis of 4'-O,3- $N$-di(ethoxycarbonyl) $\beta$-Tyrosine Ethyl Ester and 4'-O-Ethoxycarbonyl 4'-Hydroxycinnamate Ethyl Ester}

$(3 R)$ - $\beta$-tyrosine and $p$-coumarate were suspended separately in $50 \mathrm{mM}$ phosphate buffer $(1 \mathrm{~mL}$, $\mathrm{pH}$ 9.0). The amino acid and acrylate were treated with pyridine $(2 \times 0.6 \mathrm{mmol})$ and ethyl chloroformate $(2 \times 0.5 \mathrm{mmol})$ in one pot and stirred for $5 \mathrm{~min}$ each time. This step is known to partially ethyl esterify the acids; thus, excess ethanol $(\sim 150 \mu \mathrm{L})$ at $\mathrm{pH} 2(6 \mathrm{M} \mathrm{HCl})$ was added to complete the esterification. The resulting 4'-O,3-N-di(ethoxycarbonyl) ethyl ester and 4'-Oethoxycarbonyl of 4'-hydroxycinnamate ethyl ester were extracted into diethyl ether $(3 \times 1 \mathrm{~mL})$ and dried under a stream of nitrogen gas. The remaining residue from each sample was resuspended separately in 3:1 ethyl acetate/ethanol and analyzed by GC/EI-MS (Figure S4 and Figure S5). 


\section{Synthesis of 3-N-(Ethoxycarbonyl) $\beta$-Phenylalanine Methyl Ester and (E)-Cinnamate Methyl Ester Derivatives}

$(3 R)$ - $\beta$-phenylalanine and $(E)$-cinnamic acid were suspended seperately in $50 \mathrm{mM}$ phosphate buffer $(1 \mathrm{~mL}, \mathrm{pH} 9.0)$. The amino acid and acrylate were treated with pyridine $(2 \times 0.6 \mathrm{mmol})$ and ethyl chloroformate $(2 \times 0.5 \mathrm{mmol})$ in one pot and stirred for $5 \mathrm{~min}$ each time. The mixture was acidified to $\mathrm{pH}<2(6 \mathrm{M} \mathrm{HCl})$, extracted with diethyl ether $(3 \times 1 \mathrm{~mL})$, the organic layer was separated, and removed under a stream of nitrogen. The residue was resuspended in 3:1 ethyl acetate/methanol and titrated with diazomethane until a yellow color persisted. The methyl ester derivatives of $N$-acyl $\beta$-phenylalanine and methyl $(E)$-cinnamate were analyzed by GC/EI-MS (Figure S6 and Figure S7). 


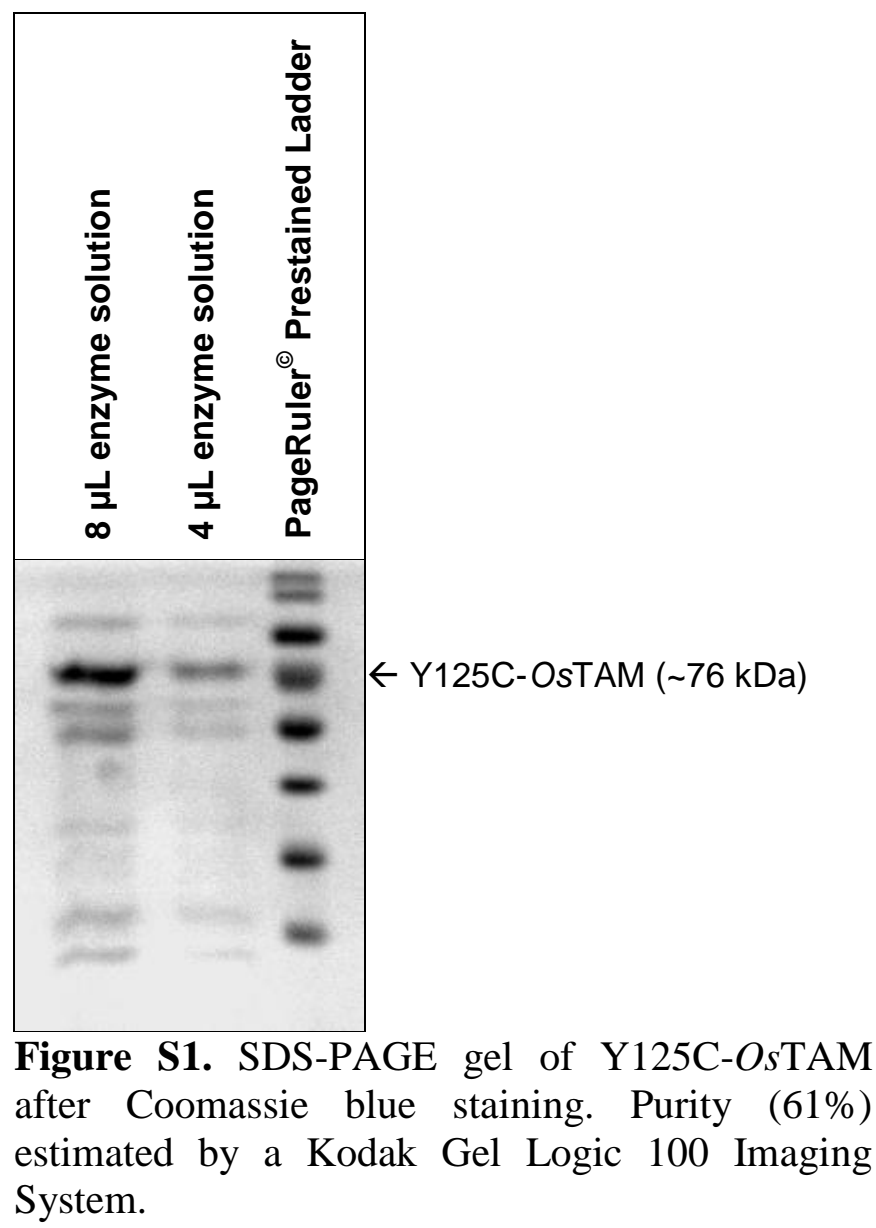




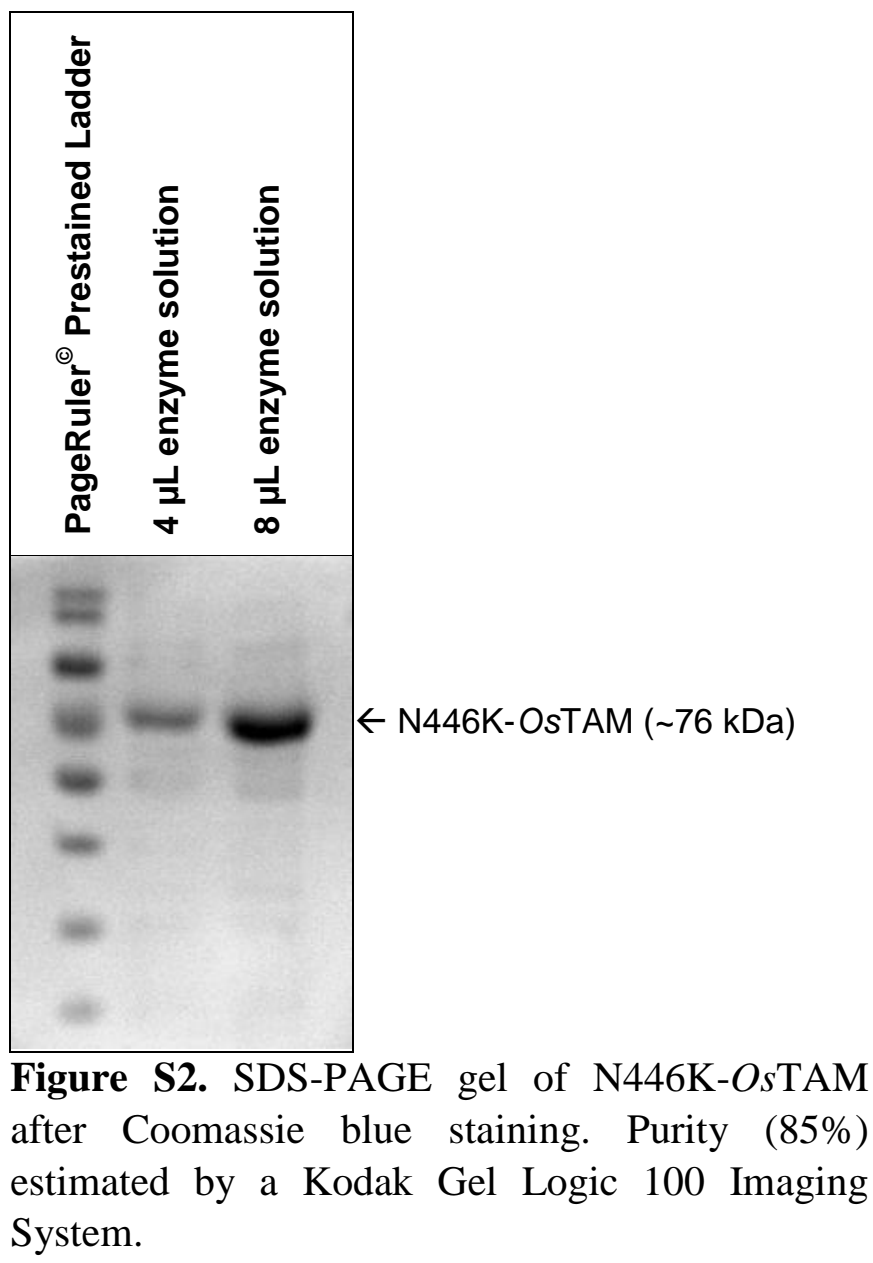




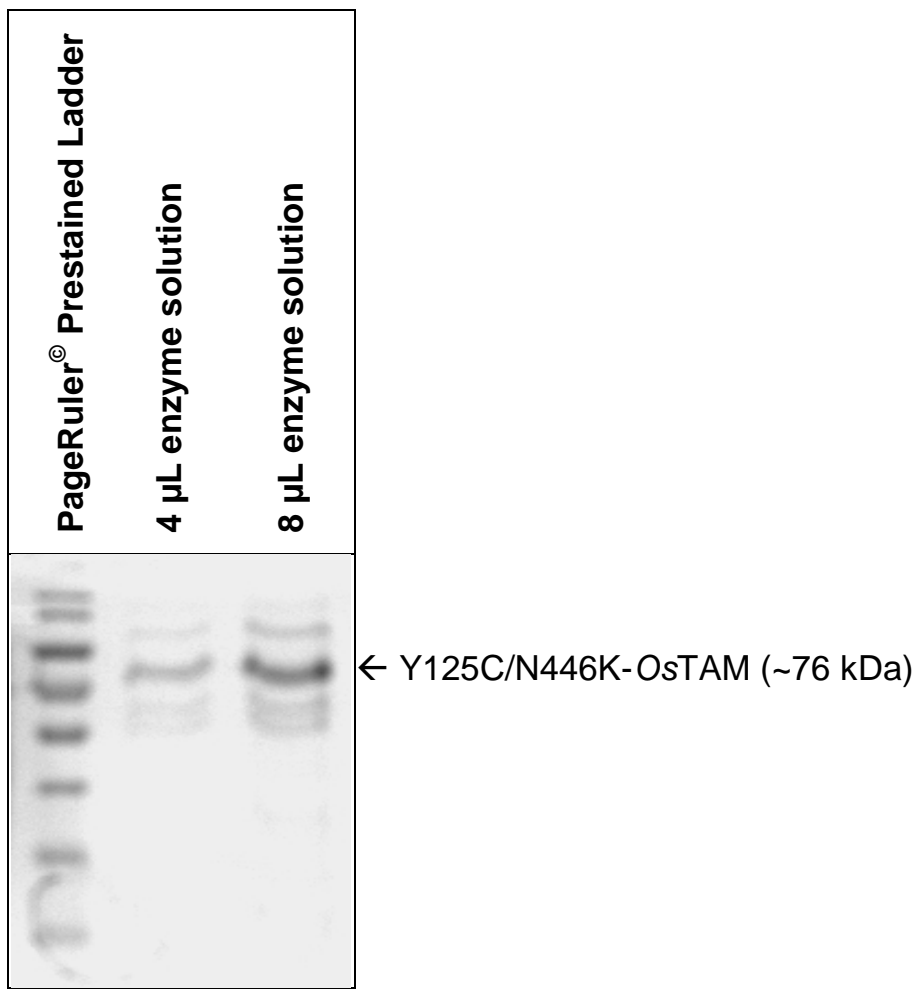

Figure S3. SDS-PAGE gel of Y125C/N446K-

OsTAM after Coomassie blue staining. Purity (65\%) estimated by a Kodak Gel Logic 100 Imaging System. 
<smiles>N[C@@H](CC(=O)[O-])c1ccc(O)cc1</smiles>

$(3 R)-\beta-$ Tyrosine
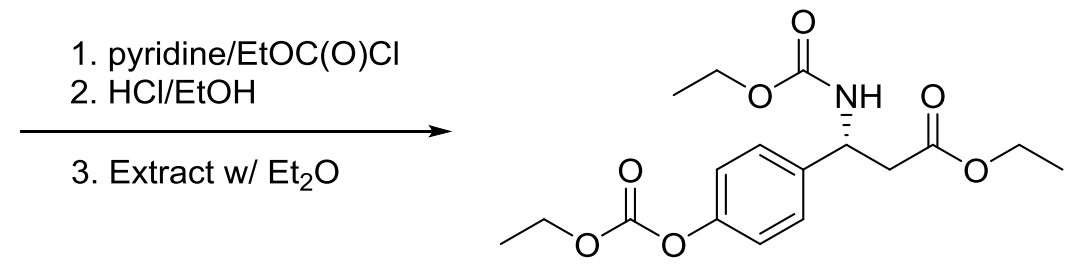

$m / z 353$<smiles>CCOC(=O)CC(N)c1ccc(OC(=O)OCC)cc1</smiles>

$m / z 280$

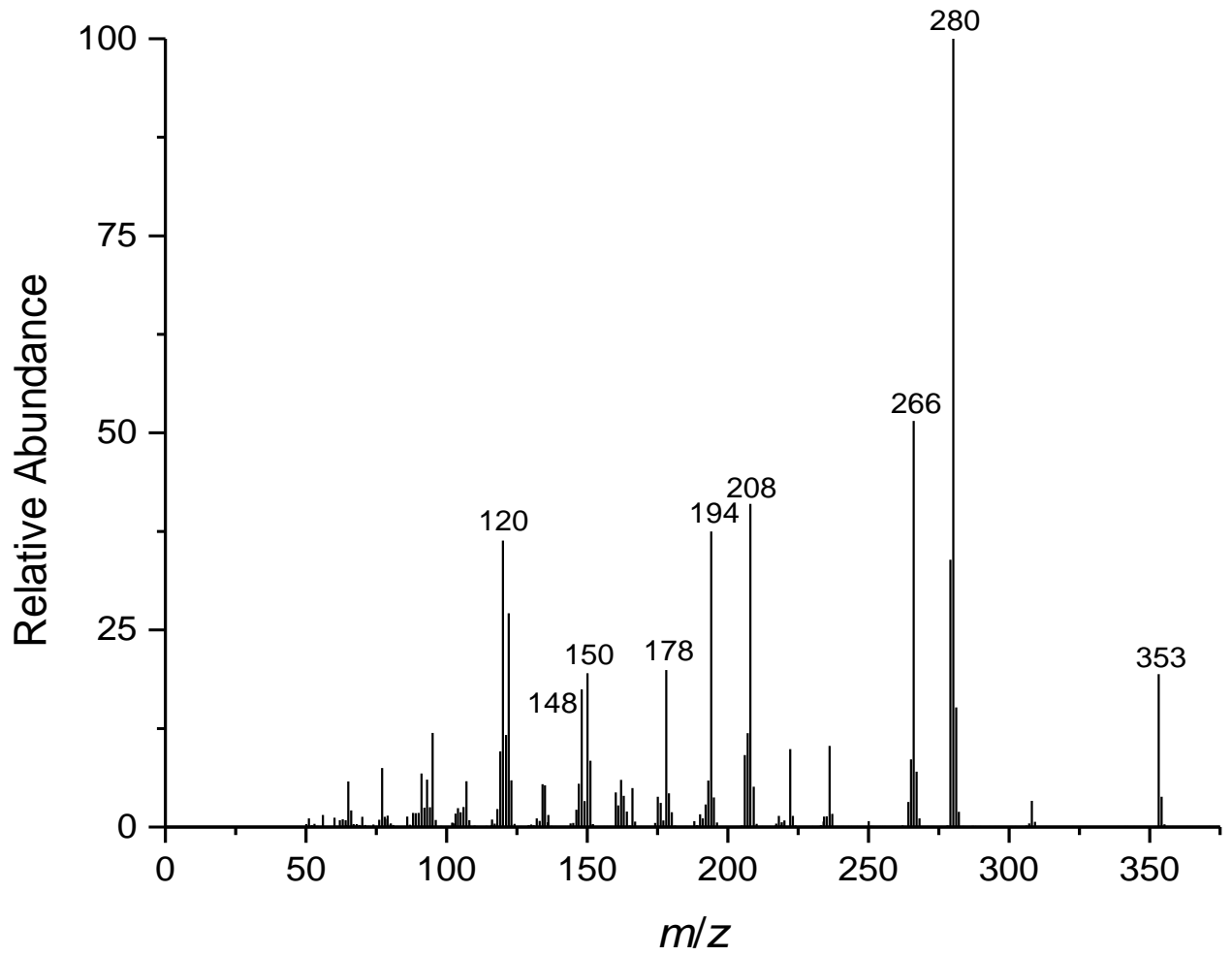

Figure S4. EI-MS of 4'-O,3-N-di(ethoxycarbonyl) ethyl ester derivative of authentic (3R)- $\beta$ tyrosine. 
<smiles>CCOC(=O)/C=C/c1ccc(OC(=O)OCC)cc1</smiles>

p-coumarate<smiles>O=C(/C=C/c1ccc(O)cc1)OCC[123I]</smiles>

$m / z 192$ $m / z 264$

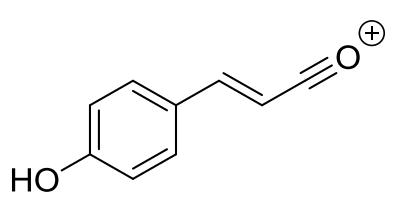

$m / z 147$

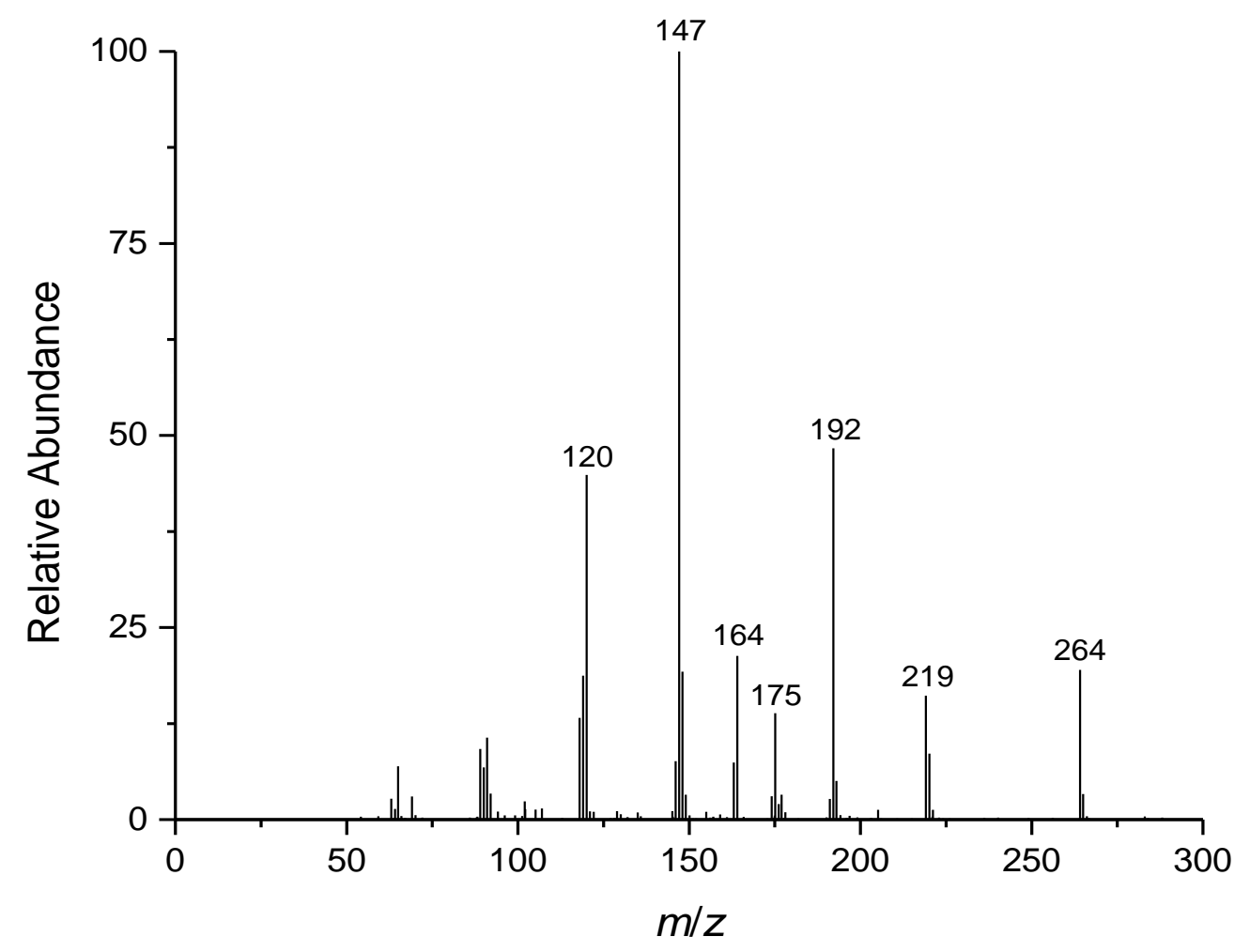

Figure S5. EI-MS of 4'- $O$-ethoxycarbonyl ethyl ester derivative of authentic 4'hydroxycinnamic acid. 


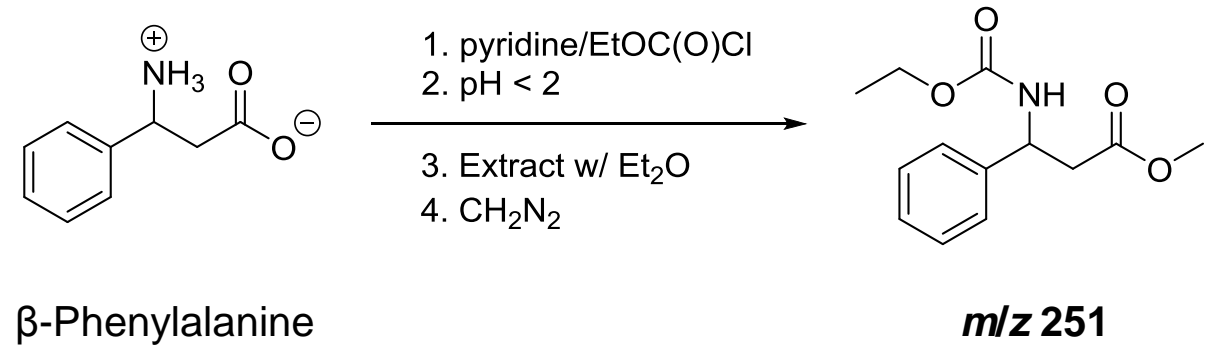

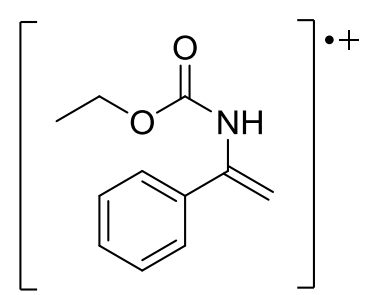

m/z 192

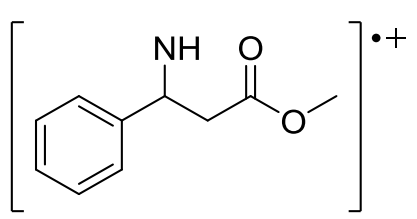

$m / z 178$<smiles>CC=Cc1ccccc1</smiles>

$m / z 104$

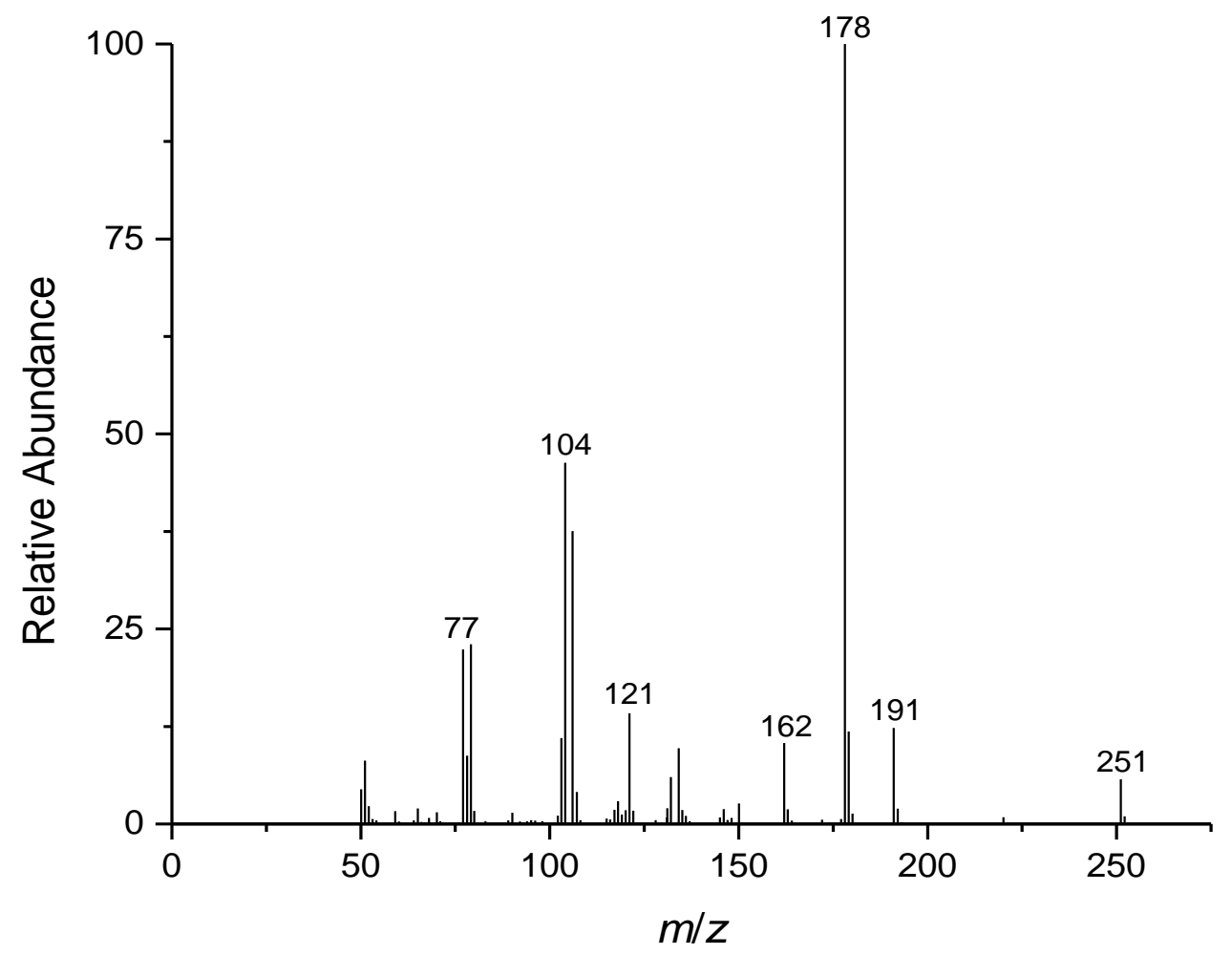

Figure S6. EI-MS of 3- $N$-ethoxycarbonyl methyl ester of authentic (3R)- $\beta$-phenylalanine. 


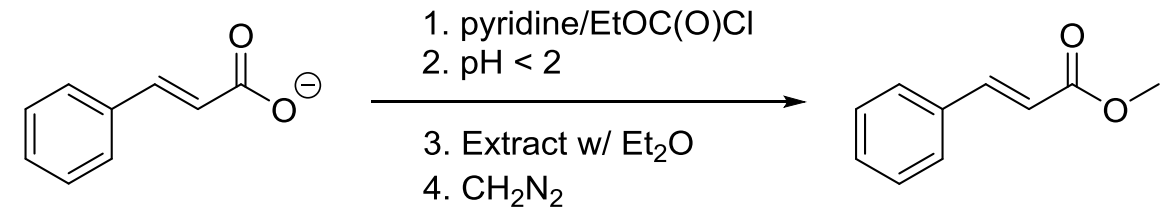

Cinnamate

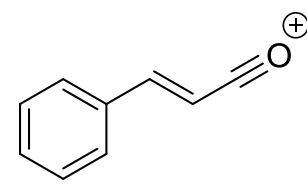

$m / z 131$ $m / z 162$<smiles>[C+]1=CC=CC=C1</smiles>

$m / z 77$

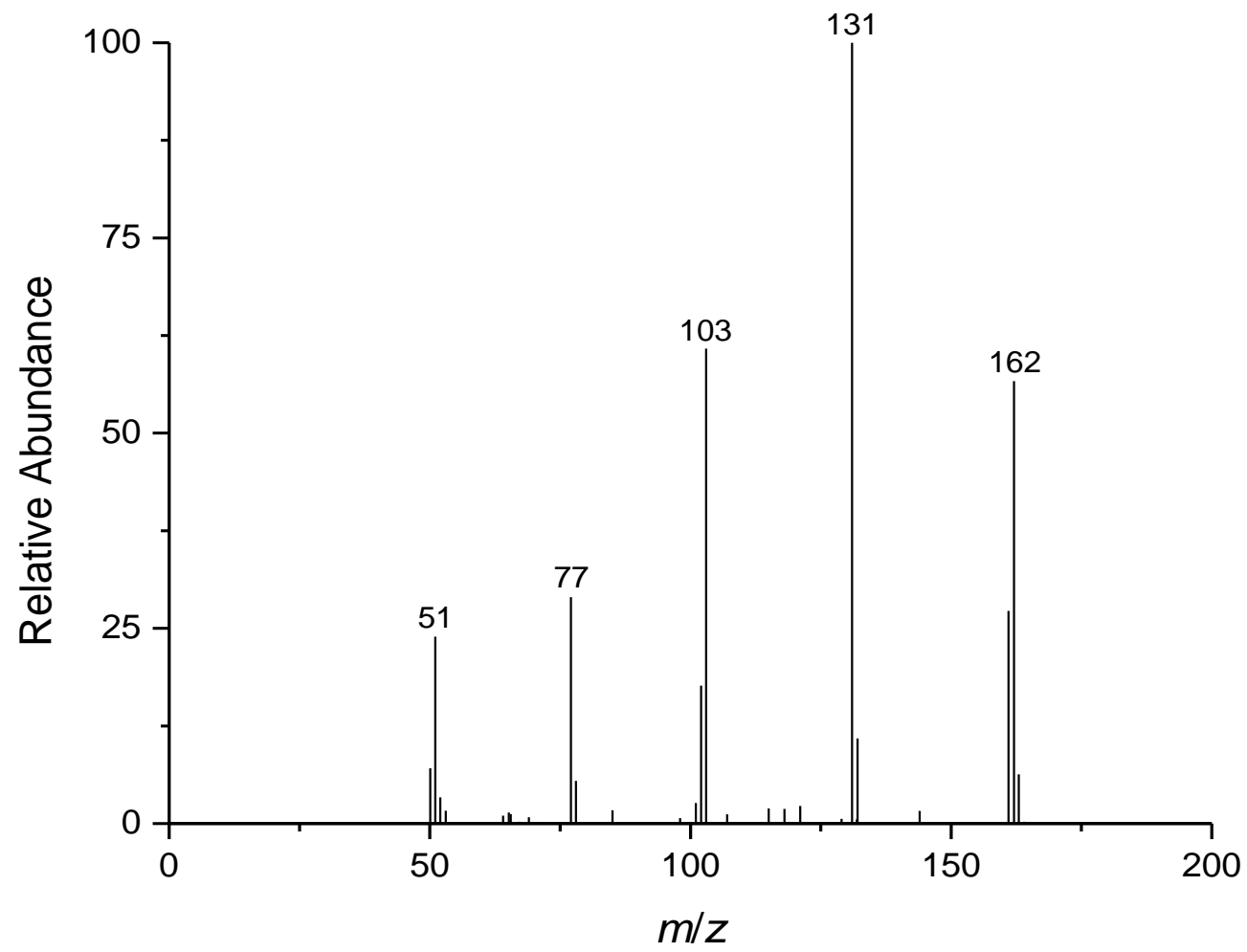

Figure S7. EI-MS of methyl ester of authentic $(E)$-cinnamate. 


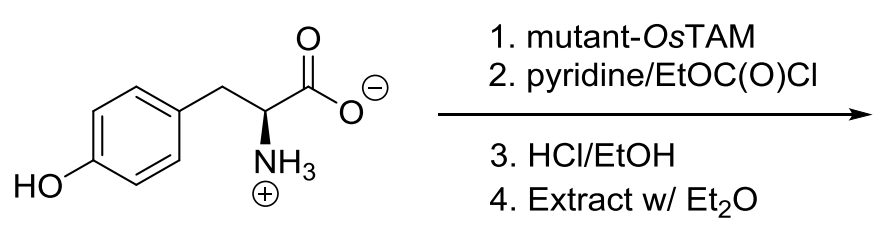

(2S)- $\alpha-$ Tyrosine<smiles>CCOC(=O)C[C@H](NC(=O)OCC)c1ccc(OC(=O)OCC)cc1</smiles>

$m / z 353$<smiles>CCOC(=O)CC(N)c1ccc(OC(=O)OCC)cc1</smiles>

$m / z 280$

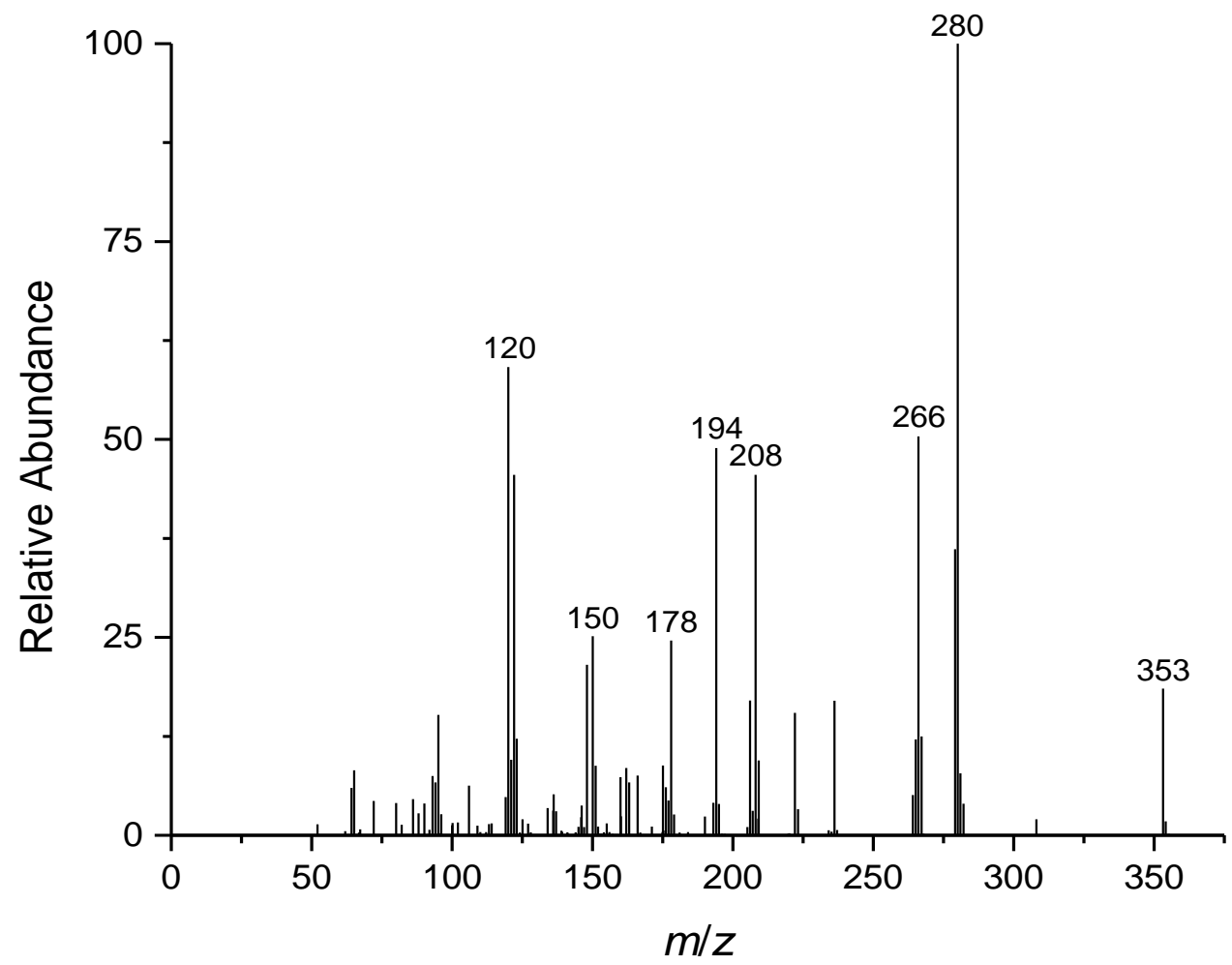

Figure S8. EI-MS of 4'-O,3- $N$-di(ethoxycarbonyl) ethyl ester derivative biosynthesized from $(2 S)$ - $\alpha$-tyrosine by Y125C-OsTAM. 


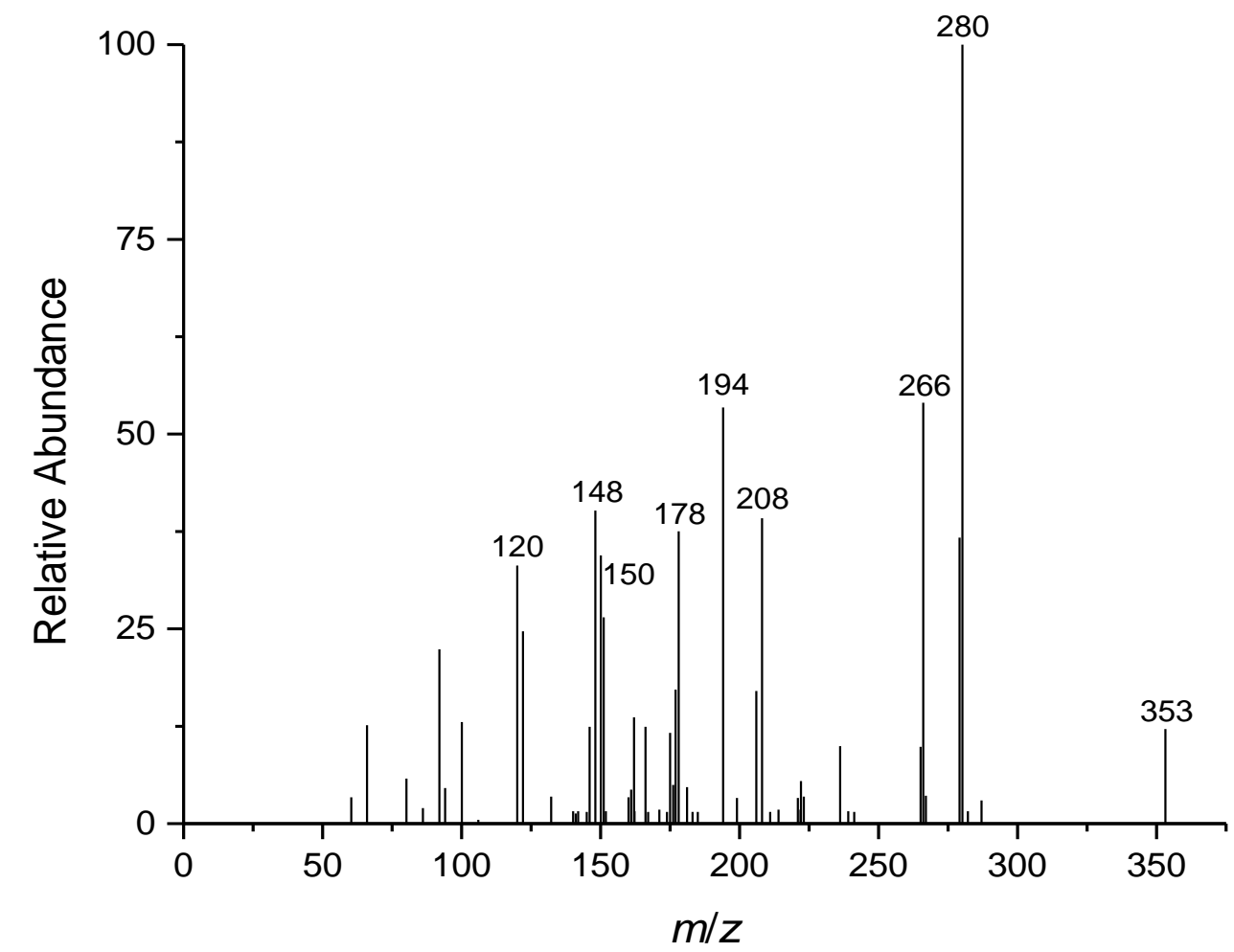

Figure S9. EI-MS of 4'- $O, 3-N$-di(ethoxycarbonyl) ethyl ester derivative biosynthesized from $(2 S)$ - $\alpha$-tyrosine by N446-OsTAM. 
<smiles>[NH3+][C@@H](Cc1ccc(O)cc1)C(=O)[O-]</smiles>

(2S)-a-Tyrosine<smiles>CCOC(=O)/C=C/c1ccc(O)cc1</smiles>

$m / z 192$
1. mutant-OsTAM

2. pyridine/EtOC $(\mathrm{O}) \mathrm{Cl}$

3. $\mathrm{HCl} / \mathrm{EtOH}$

4. Extract $\mathrm{w} / \mathrm{Et}_{2} \mathrm{O}$<smiles>CCOC(=O)/C=C/c1ccc(OC(=O)OCC)cc1</smiles>

$m / z 264$<smiles></smiles>

$m / z 147$

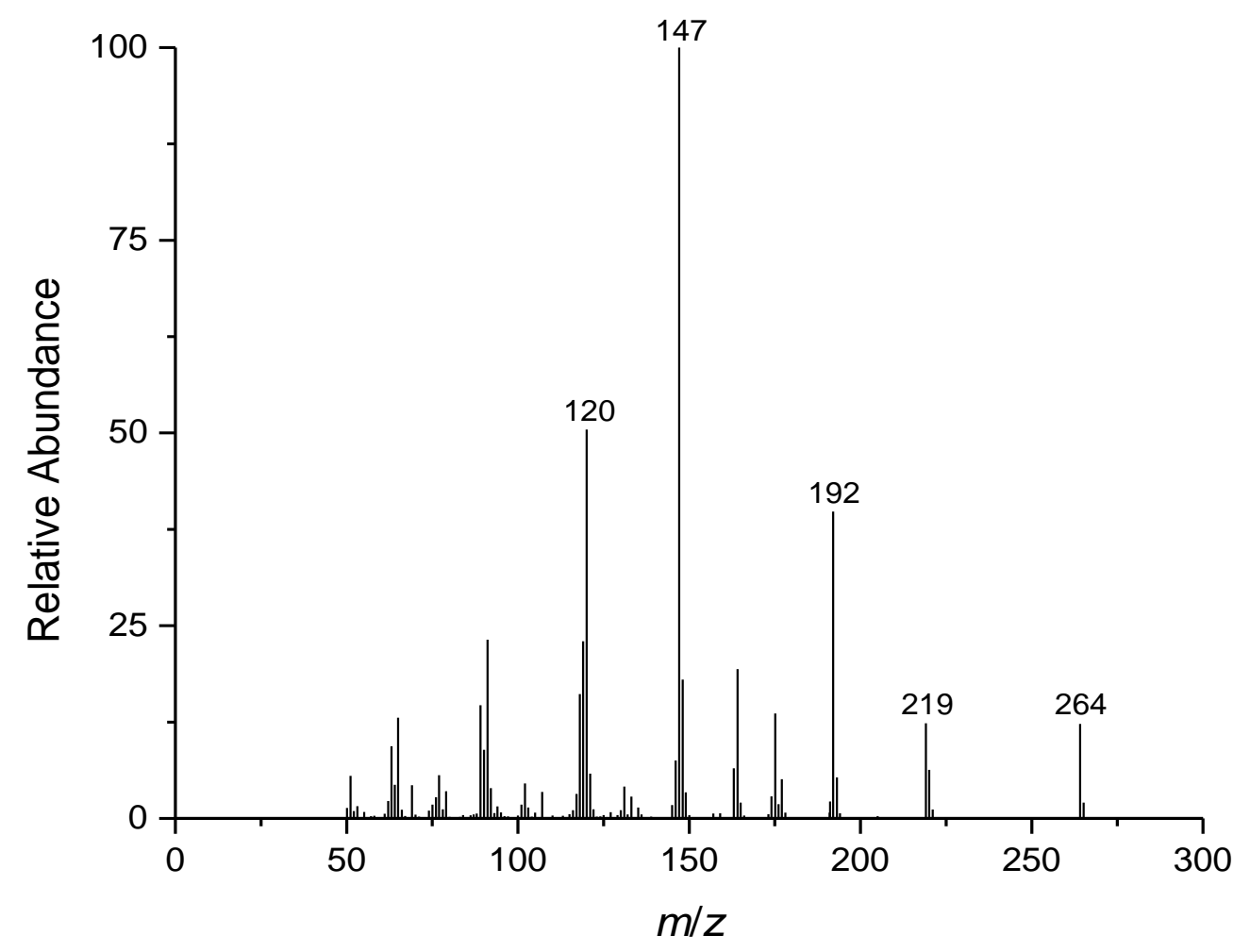

Figure S10. EI-MS of 4'- $O$-ethoxycarbonyl ethyl ester derivative of 4'-hydroxycinnamic acid biosynthesized from $(2 S)$ - $\alpha$-tyrosine by Y125C-OsTAM. 


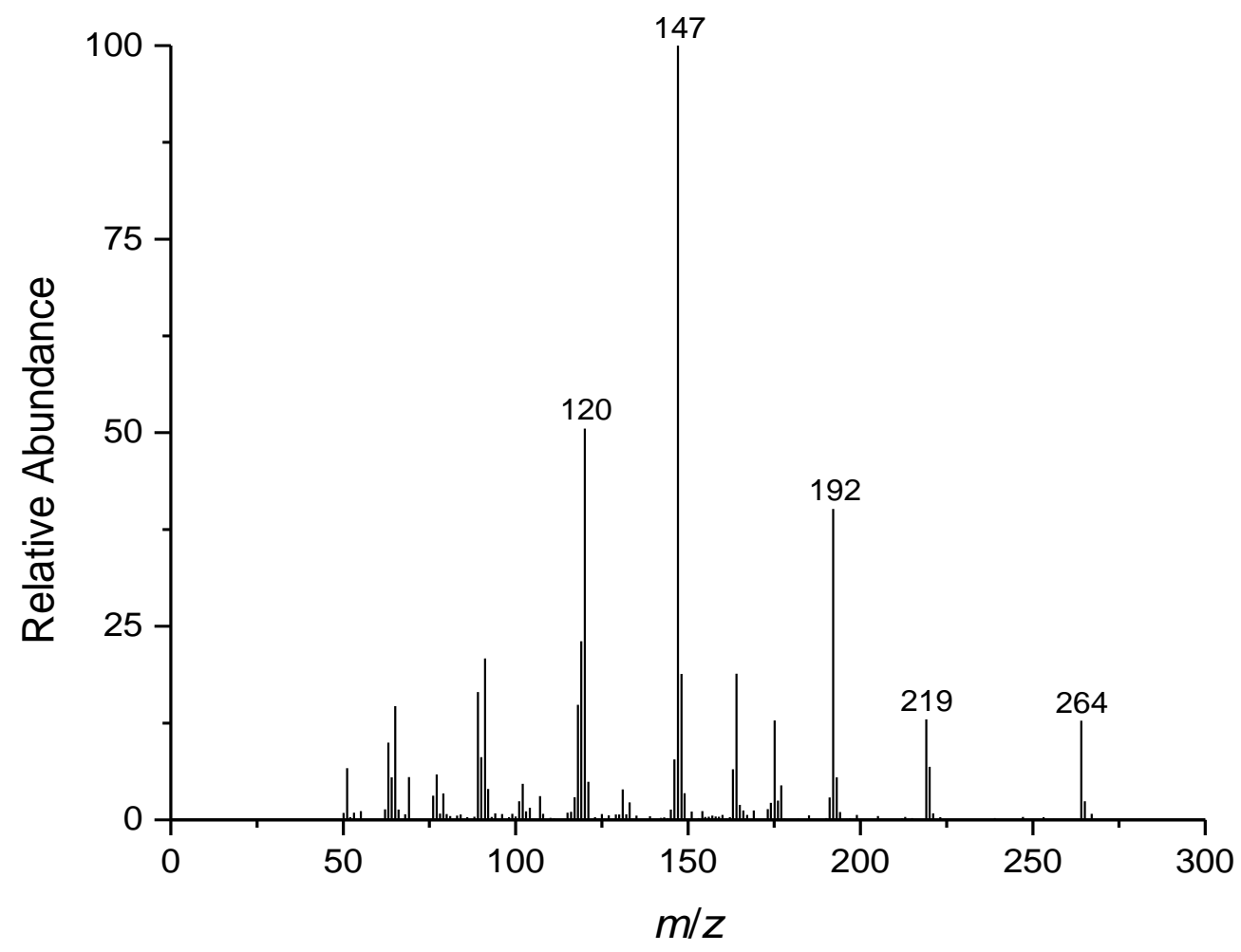

Figure S11. EI-MS of 4'-O-ethoxycarbonyl ethyl ester derivative of 4'-hydroxycinnamic acid biosynthesized from $(2 S)$ - $\alpha$-tyrosine by N446K-OsTAM.
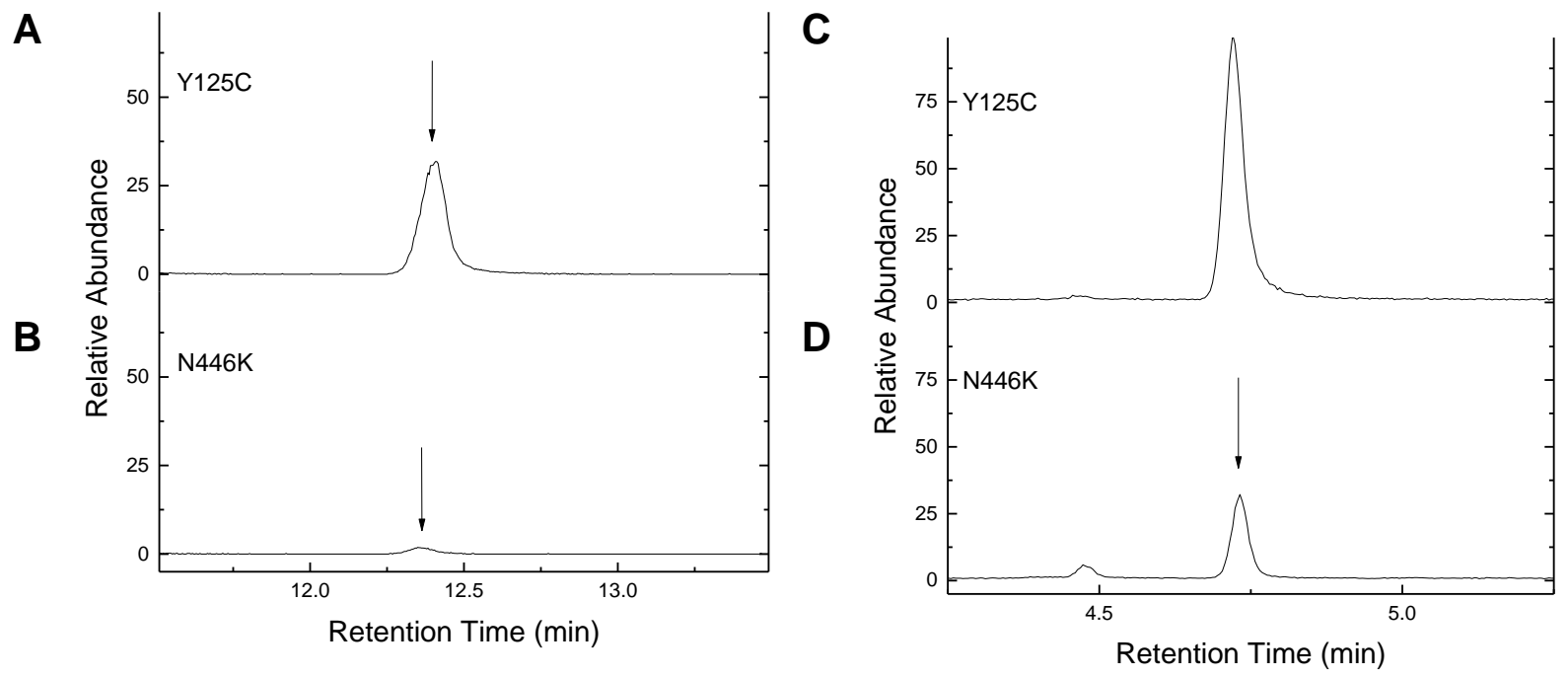

Figure S12. Partial extracted ion chromatograms for the 4'-O,3- $N$-di(ethoxycarbonyl) ethyl ester derivative of $\beta$-tyrosine $(\mathrm{m} / \mathrm{z}, 280)$ produced over $18 \mathrm{~h}$ by (A) Y125C-OsTAM and (B) N446K-OsTAM and 4'-O-ethoxycarbonyl derivative of $p$-coumarate $(\mathrm{m} / z$ 147) produced over $18 \mathrm{~h}$ by (C) Y125C-OsTAM and (D) N446K-OsTAM. Peaks of interest indicated by arrows. 


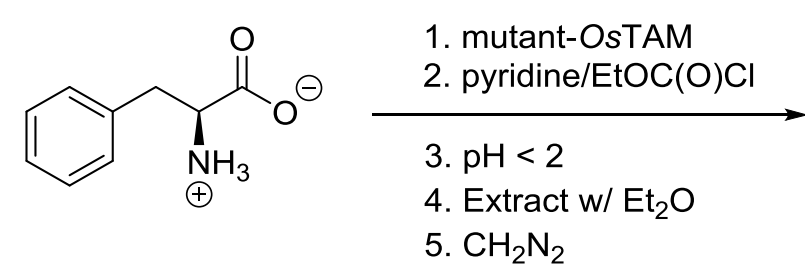

a-Phenylalanine<smiles>C=C(NC(=O)OCC)c1ccccc1</smiles>

$m / z 191$<smiles>COC(=O)CC(N)c1ccccc1</smiles>

$m / z 178$<smiles>CCOC(=O)NC(CC(=O)OC)c1ccccc1</smiles>

$m / z 251$

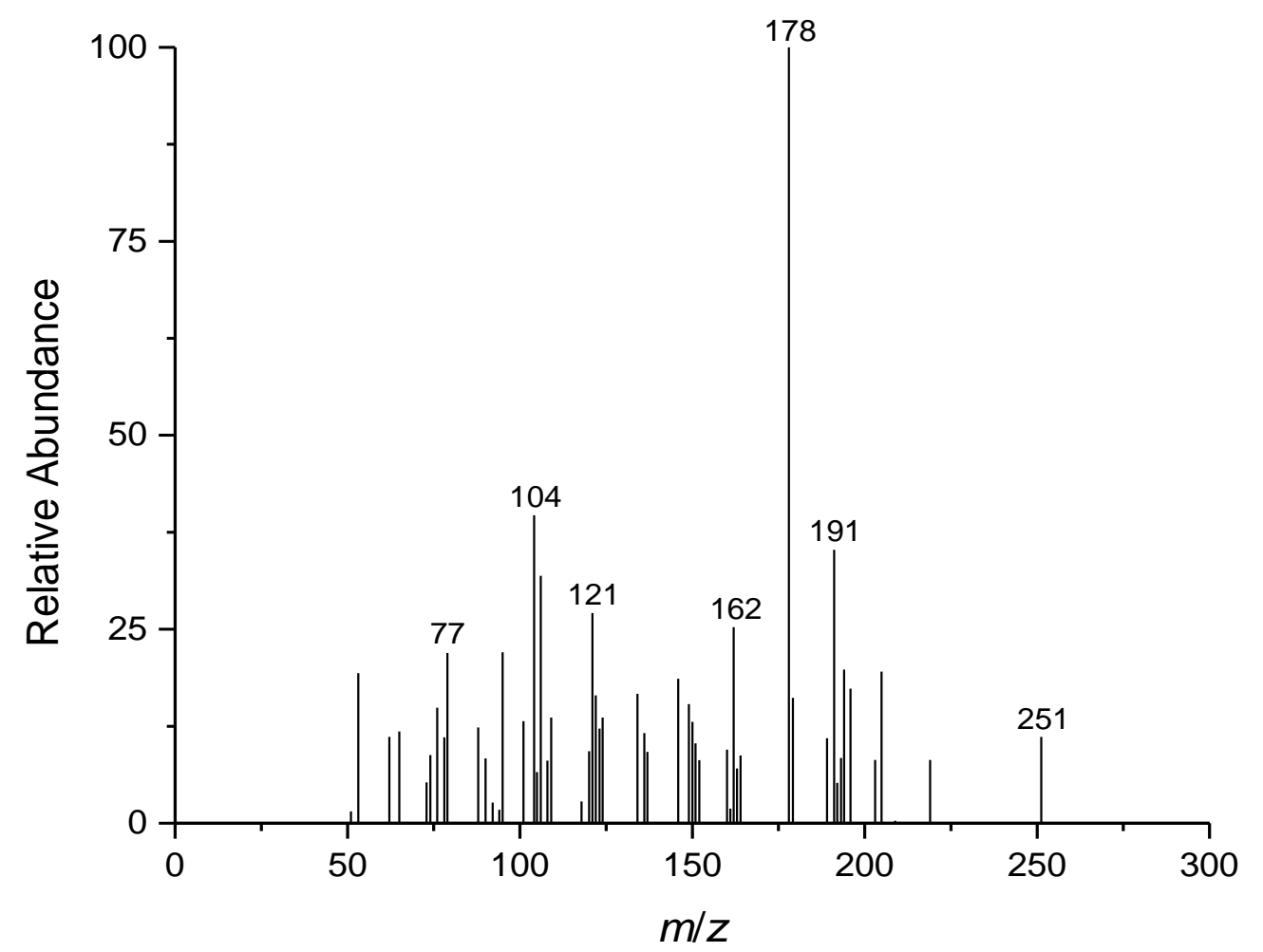

Figure S13. EI-MS of 3- $N$-ethoxycarbonyl methyl ester of $\beta$-tyrosine biosynthesized from (2S)$\alpha$-phenylalanine by Y125C-OsTAM. 


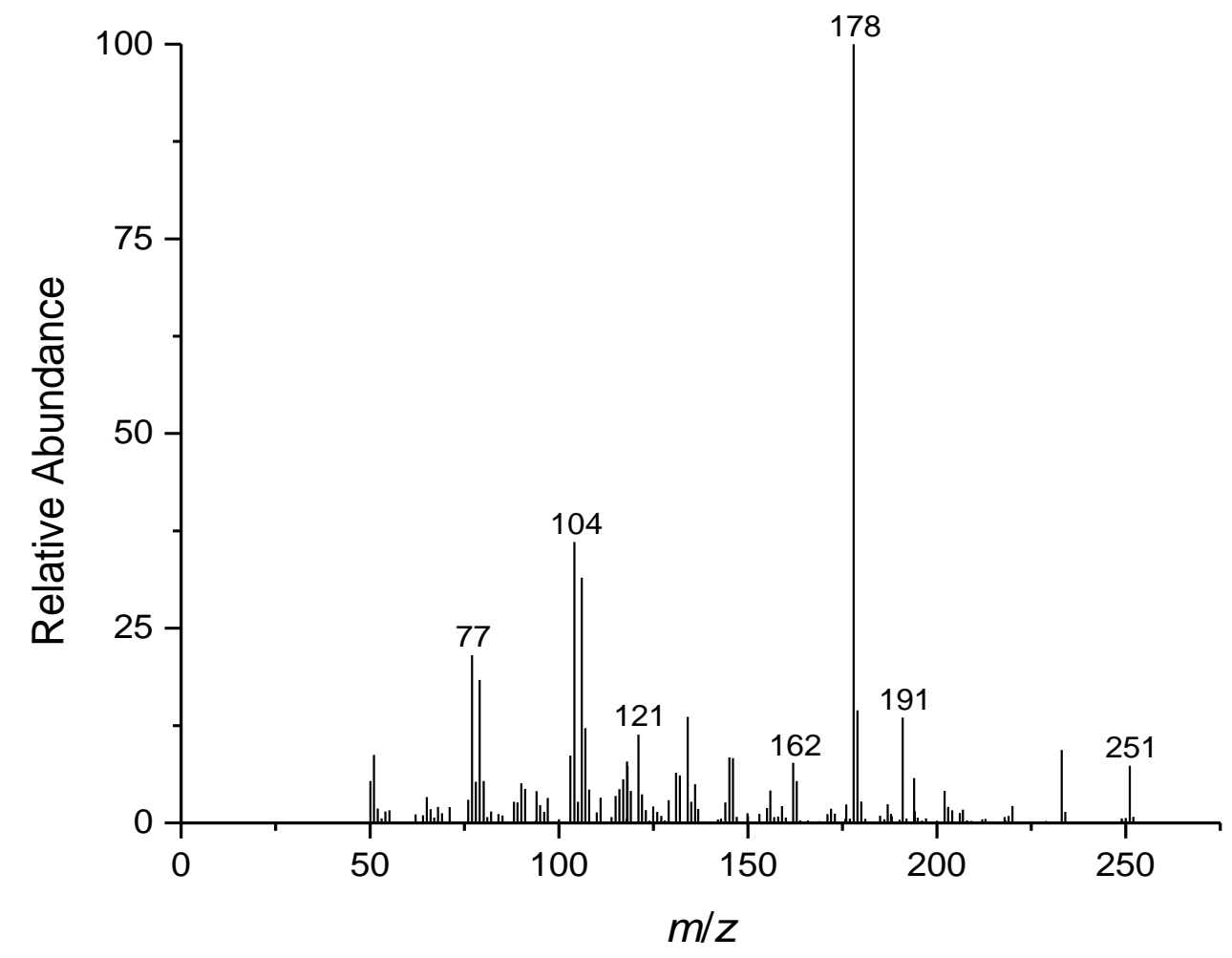

Figure S14. EI-MS of 3- $N$-ethoxycarbonyl methyl ester of $\beta$-tyrosine biosynthesized from (2S)- $\alpha$-phenylalanine by N446K-OsTAM.

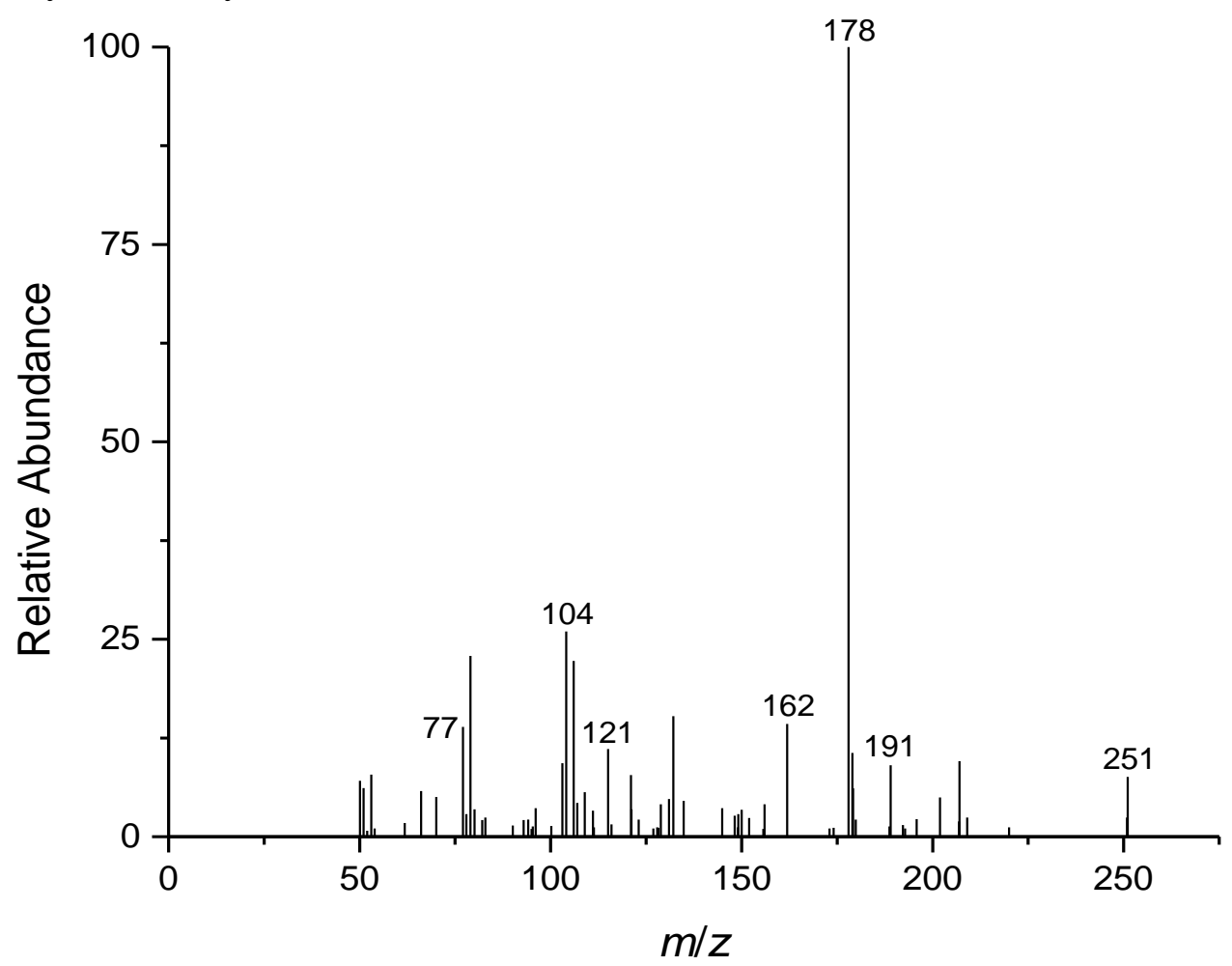

Figure S15. EI-MS of 3- $N$-ethoxycarbonyl methyl ester of $\beta$-tyrosine biosynthesized from (2S)- $\alpha$-phenylalanine by Y125C/N446K-OsTAM. 
<smiles>[NH3+][C@@H](Cc1ccccc1)C(=O)[O-]</smiles>

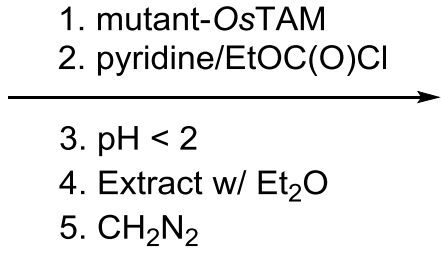

a-Phenylalanine

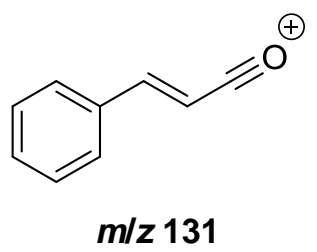

$m / z 162$

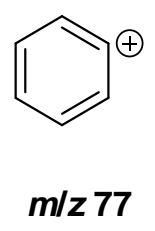

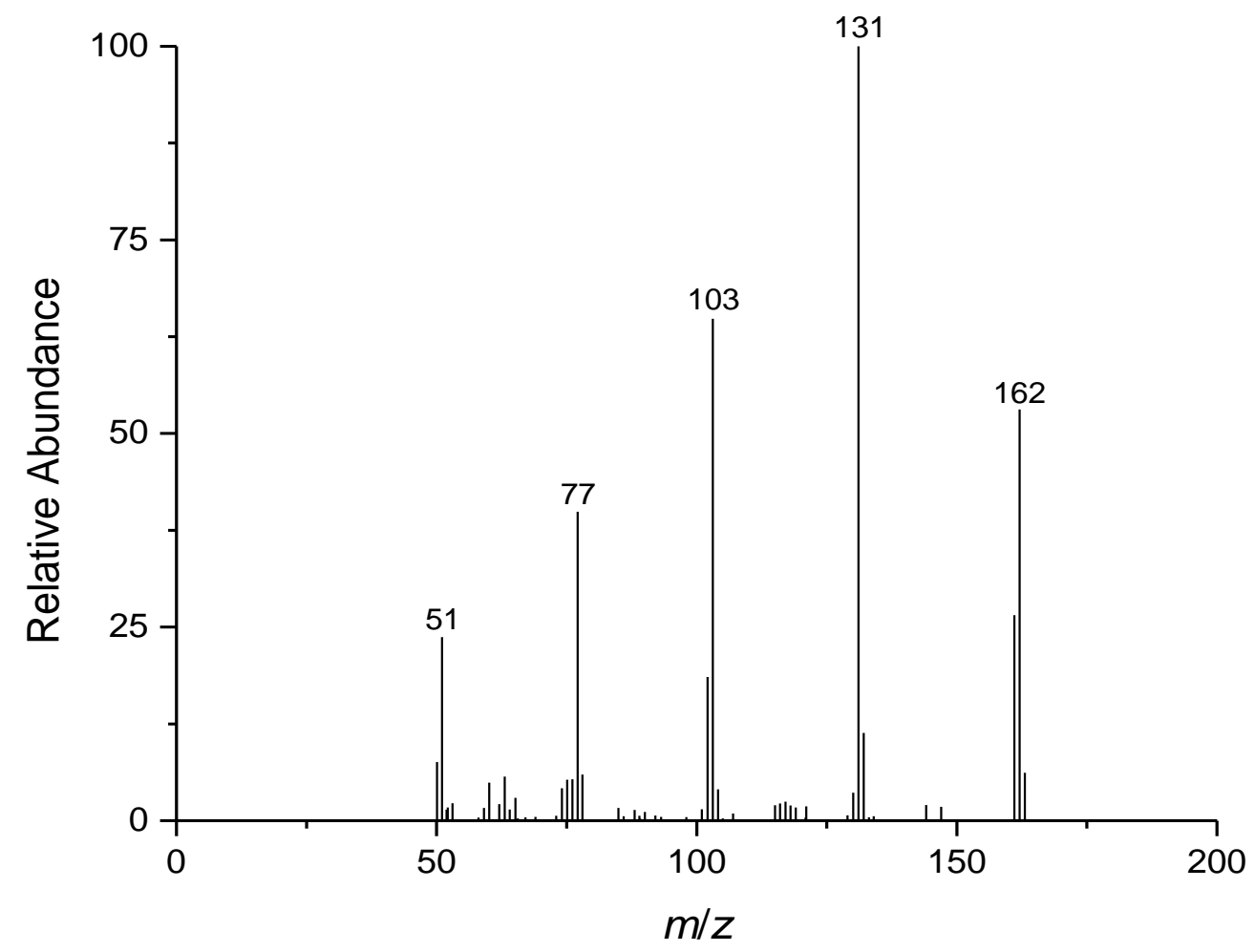

Figure S16. EI-MS of methyl ester of $(E)$-cinnamate biosynthesized from $(2 S)$ - $\alpha$-phenylalanine by $\mathrm{Y} 125 \mathrm{C}-O s \mathrm{TAM}$. 


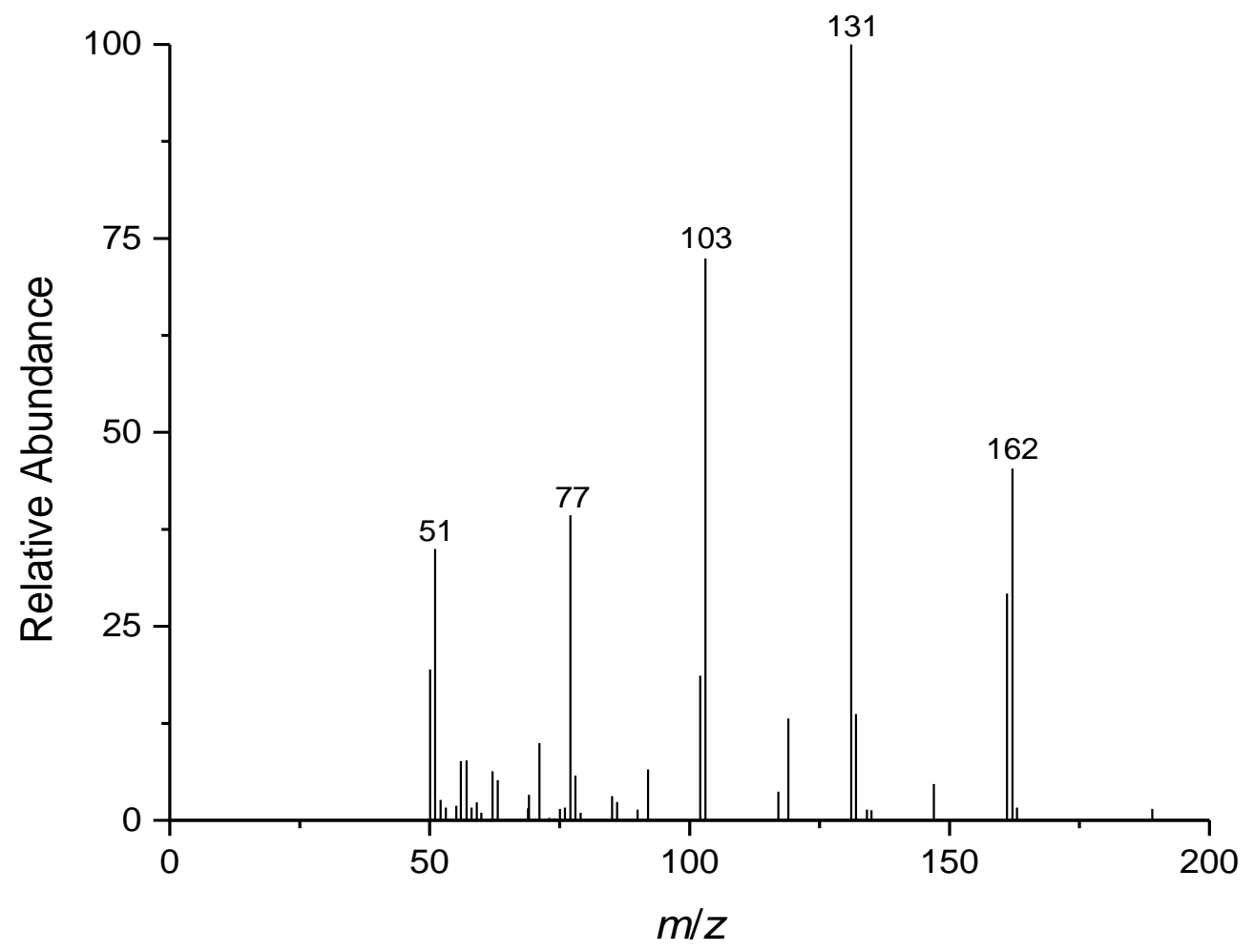

Figure S17. EI-MS of methyl ester of $(E)$-cinnamate biosynthesized from (2S)- $\alpha$ phenylalanine by N446K-OsTAM.

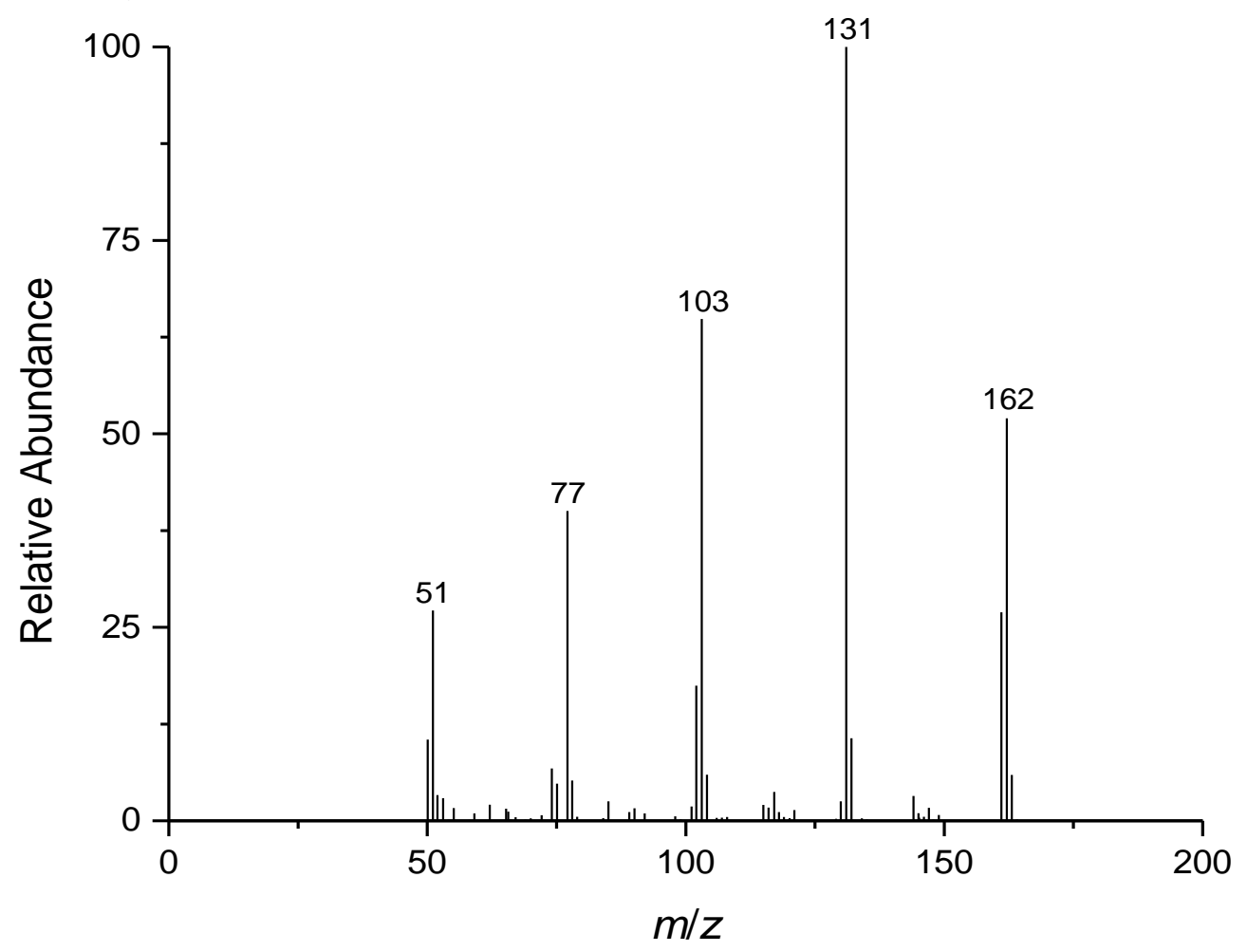

Figure S18. EI-MS of methyl ester of $(E)$-cinnamate biosynthesized from $(2 S)-\alpha-$ phenylalanine by $\mathrm{Y} 125 \mathrm{C} / \mathrm{N} 446 \mathrm{~K}-O s \mathrm{TAM}$. 

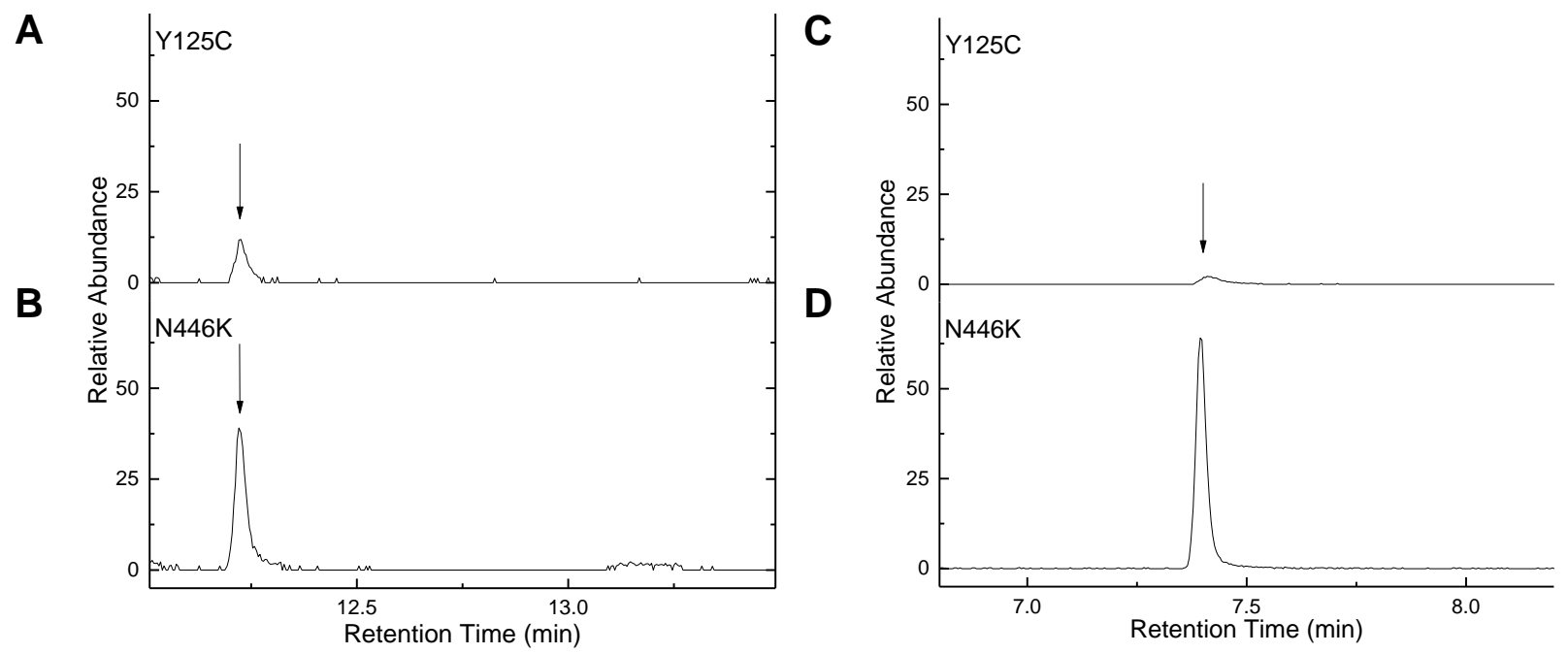

Figure S19. Partial extracted ion chromatograms for the 3- $N$-ethoxycarbonyl methyl ester derivative of $\beta$-phenylalanine $(\mathrm{m} / \mathrm{z}$ 178) produced over $18 \mathrm{~h}$ by (A) Y125C-OsTAM and (B) $\mathrm{N} 446 \mathrm{~K}-O s \mathrm{TAM}$ and the methyl ester of $(E)$-cinnamate $(\mathrm{m} / \mathrm{z}, 131)$ produced over $18 \mathrm{~h}$ by $(\mathrm{C})$ Y125C-OsTAM and (D) N446K-OsTAM. Peaks of interest indicated by arrows.

A
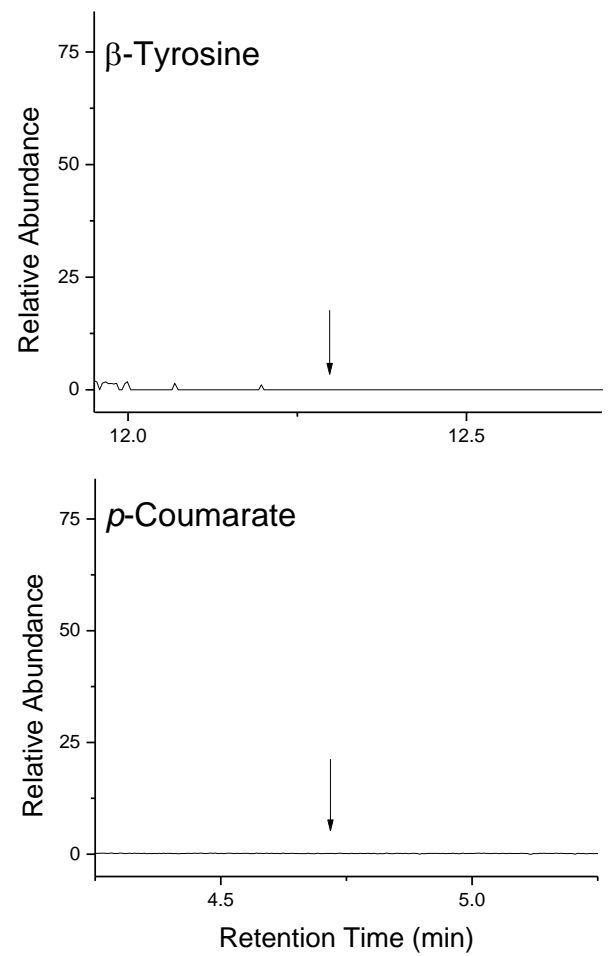

B
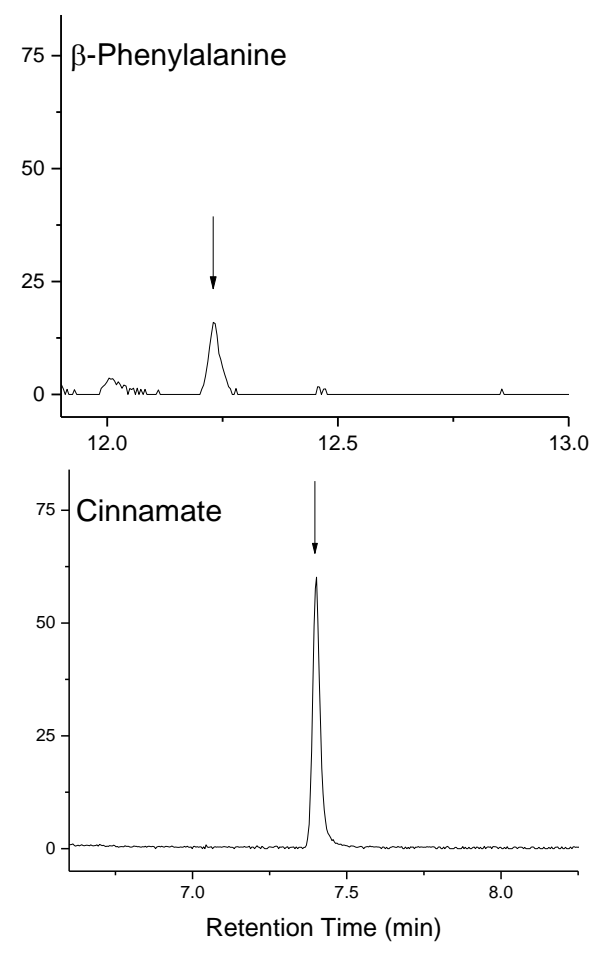

Figure S20. Partial ion extracted chromatograms for (A) the 4'-O,3- $N$-di(ethoxycarbonyl) ethyl ester derivative of $\beta$-phenylalanine $(\mathrm{m} / \mathrm{z}, 280)$ and the 4'-O-ethoxycarbonyl ethyl ester derivative of $p$-coumarate $(\mathrm{m} / \mathrm{z}, 147)$, and (B) the 3- $\mathrm{N}$-ethoxycarbonyl methyl ester derivative of $\beta$-phenylalanine $(\mathrm{m} / \mathrm{z} 178)$ and methyl ester of $(E)$-cinnamate $(\mathrm{m} / \mathrm{z} 131)$ produced over $18 \mathrm{~h}$ 
for Y125C/N446K-OsTAM. Peaks of interest indicated by arrows.

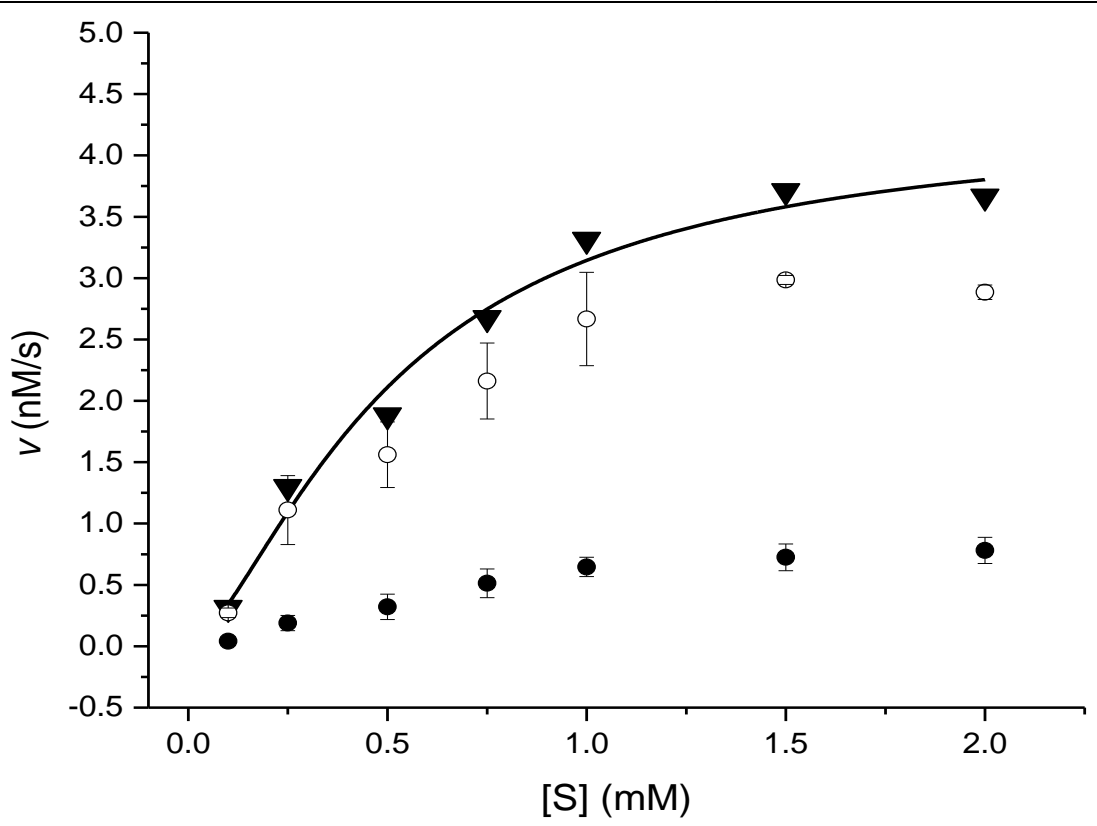

Figure S21. Non-linear regression plot $\left(v=k_{\text {cat }}^{\text {total }}[\mathrm{E}]_{\mathrm{o}}[\mathrm{S}] /\left(K_{\mathrm{M}}+[\mathrm{S}]\right)\right)$ for total product ( $\beta$-tyrosine + coumarate) biosynthesized by Y125C-OsTAM $(\boldsymbol{\nabla})$. The steady state productions of $\beta$-tyrosine $(\bullet)$ and coumarate $(0)$ are plotted separately. $k_{\text {cat }}^{\text {total }}=k_{\text {cat }}^{\beta-T y r}+k_{\text {cat }}^{\text {Coum }} . K_{\mathrm{M}}=0.51 \mathrm{mM}, k_{\text {cat }}^{\beta-\mathrm{Tyr}}=5.3 \times 10^{-5} \mathrm{~s}^{-1}$, $k_{\text {cat }}^{\text {Coum }}=1.8 \times 10^{-4} \mathrm{~s}^{-1}$.

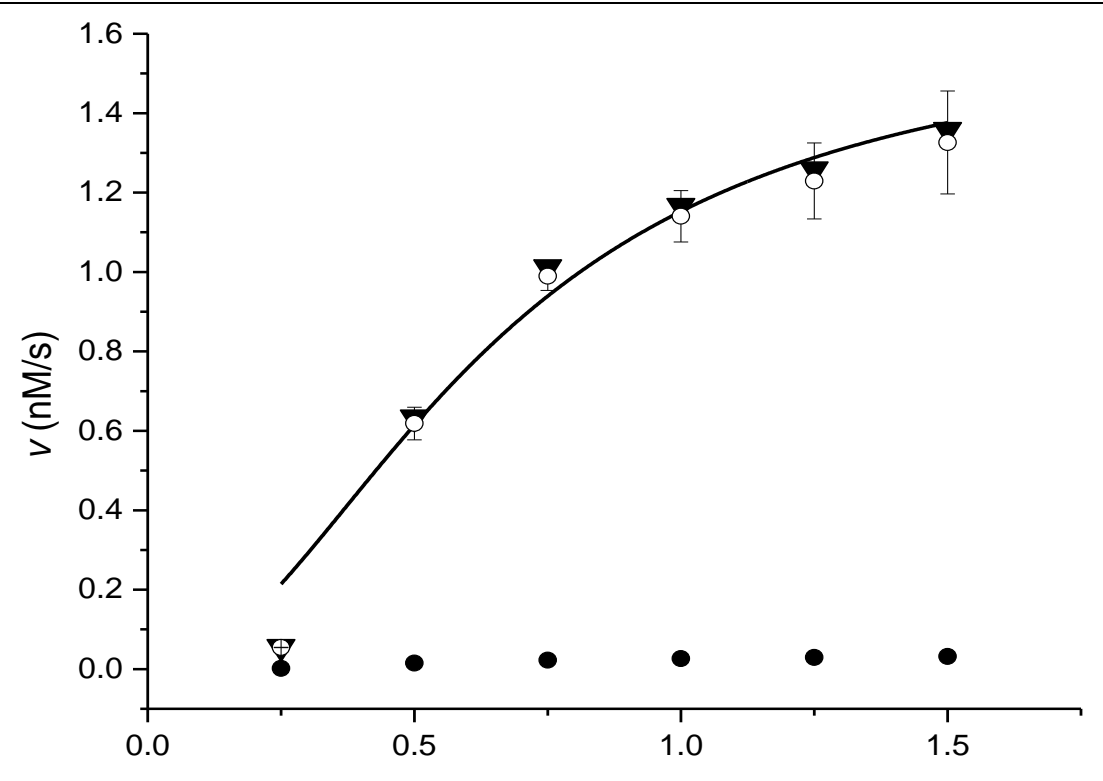

[S] $(\mathrm{mM})$

Figure S22. Non-linear regression plot $\left(v=k_{\text {cat }}^{\text {total }}[\mathrm{E}]_{\mathrm{o}}[\mathrm{S}] /\left(K_{\mathrm{M}}+[\mathrm{S}]\right)\right)$ for a total product ( $\beta$-tyrosine + coumarate) biosynthesized by N446K-OsTAM $(\boldsymbol{\nabla})$. The steady state productions of $\beta$-tyrosine $(\bullet)$ and coumarate $(0)$ are plotted separately. $k_{\text {cat }}^{\text {total }}=k_{\text {cat }}^{\beta-\mathrm{Tyr}}+k_{\text {cat }}^{\text {Coum }} \cdot K_{\mathrm{M}}=0.64 \mathrm{mM}, k_{\text {cat }}^{\beta-\mathrm{Tyr}}=2.1 \times 10^{-6} \mathrm{~s}^{-1}$, $k_{\text {cat }}^{\text {Coum }}=8.6 \times 10^{-5} \mathrm{~s}^{-1}$. 


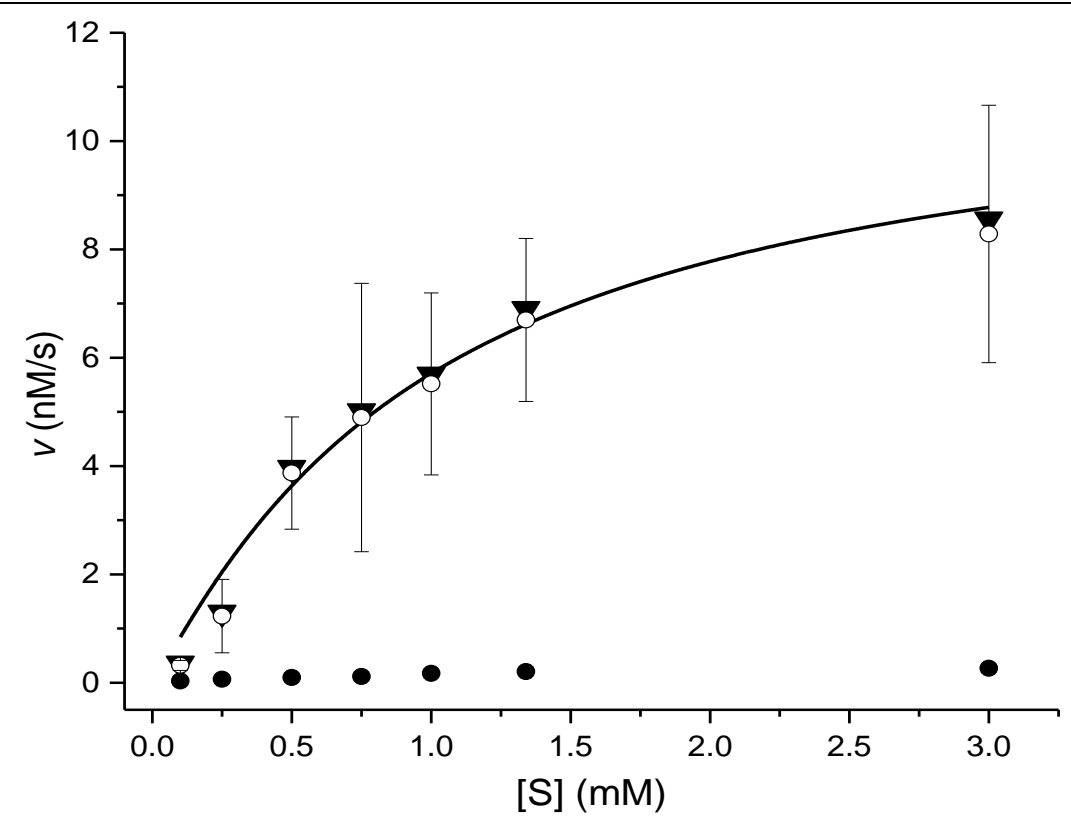

Figure S23. Non-linear regression plot $\left(v=k_{\text {cat }}^{\text {total }}[\mathrm{E}]_{\mathrm{o}}[\mathrm{S}] /\left(K_{\mathrm{M}}+[\mathrm{S}]\right)\right)$ for a total product $(\beta$-phenylalanine + cinnamate) biosynthesized by $\mathrm{Y} 125 \mathrm{C}$ OsTAM $(\boldsymbol{\nabla})$. The steady state productions of $\beta$-phenylalanine $(\bullet)$ and cinnamate (o) are plotted separately. $k_{\text {cat }}^{\text {total }}=k_{\text {cat }}^{\beta-\text { Phe }}+k_{\text {cat }}^{\text {Cinn }} . K_{\mathrm{M}}=1.0 \mathrm{mM}$, $k_{\text {cat }}^{\beta-\text { Phe }}=3.5 \times 10^{-5} \mathrm{~s}^{-1}, k_{\text {cat }}^{\text {Cinn }}=1.2 \times 10^{-3} \mathrm{~s}^{-1}$.

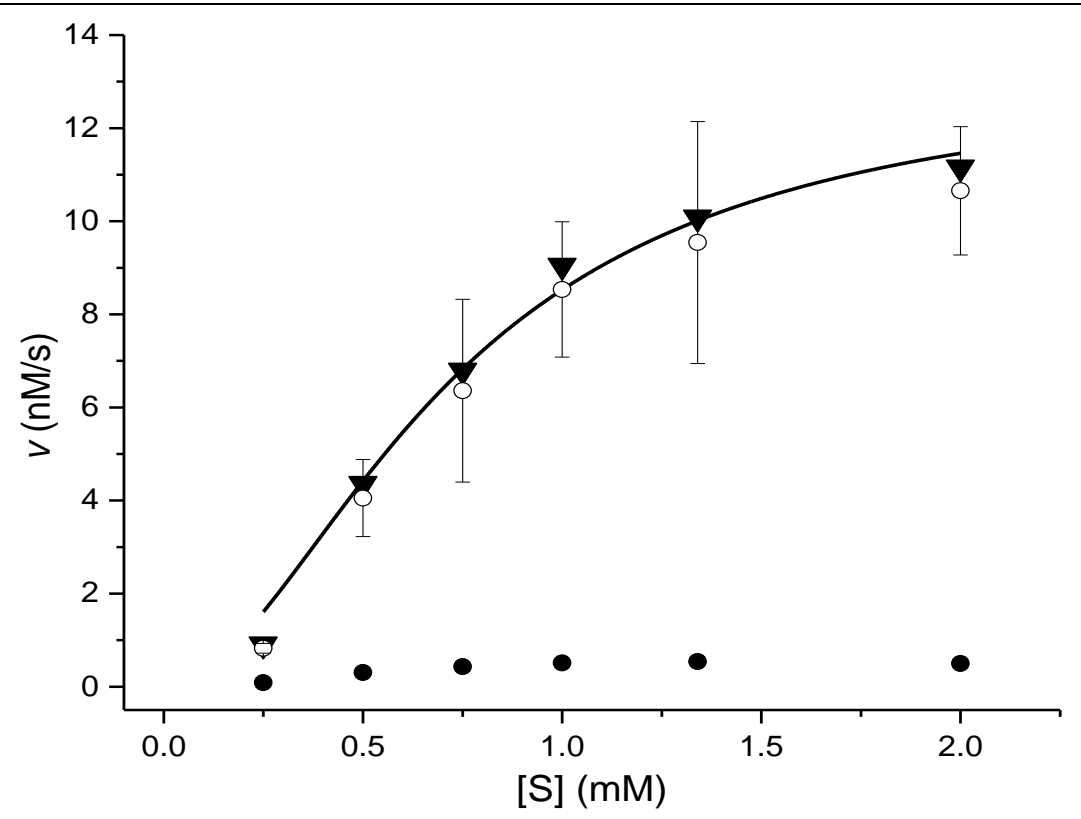

Figure S24. Non-linear regression plot $\left(v=k_{\text {cat }}^{\text {total }}[\mathrm{E}]_{\mathrm{o}}[\mathrm{S}] /\left(K_{\mathrm{M}^{+}}+[\mathrm{S}]\right)\right)$ for a total product $(\beta$-phenylalanine + cinnamate) biosynthesized by $\mathrm{N} 446 \mathrm{~K}$ OsTAM $(\boldsymbol{\nabla})$. The steady state productions of $\beta$-phenylalanine $(\bullet)$ and cinnamate (o) are plotted separately. $k_{\mathrm{cat}}^{\text {total }}=k_{\mathrm{cat}}^{\beta-\mathrm{Phe}}+k_{\mathrm{cat}}^{\mathrm{Cinn}} \cdot K_{\mathrm{M}}=0.72$ 
$\mathrm{mM}, k_{\text {cat }}^{\beta-P h e}=8.0 \times 10^{-5} \mathrm{~s}^{-1}, k_{\mathrm{cat}}^{\text {Cinn }}=1.3 \times 10^{-3} \mathrm{~s}^{-1}$.

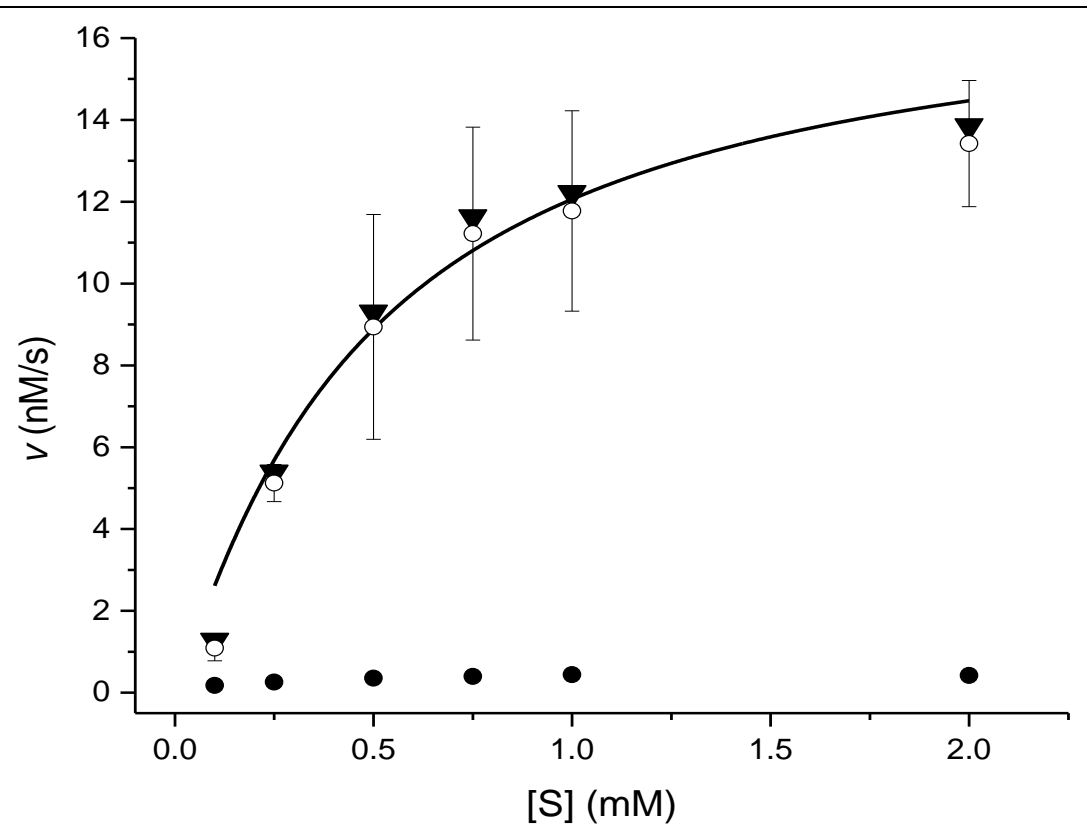

Figure S25. Non-linear regression plot $\left(v=k_{\text {cat }}^{\text {total }}[\mathrm{E}]_{\mathrm{o}}[\mathrm{S}] /\left(K_{\mathrm{M}}+[\mathrm{S}]\right)\right)$ for a total product ( $\beta$-phenylalanine + cinnamate) biosynthesized by $\mathrm{Y} 125 \mathrm{C} / \mathrm{N} 446 \mathrm{~K}$ $\operatorname{OsTAM}(\boldsymbol{\nabla})$. The steady state productions of $\beta$-phenylalanine $(\bullet)$ and cinnamate (O) are plotted separately. $k_{\text {cat }}^{\text {total }}=k_{\text {cat }}^{\beta-P h e}+k_{\text {cat }}^{\text {Cinn }} \cdot K_{\mathrm{M}}=0.49 \mathrm{mM}$, $k_{\text {cat }}^{\beta-P h e}=5.2 \times 10^{-5} \mathrm{~s}^{-1}, k_{\mathrm{cat}}^{\mathrm{Cinn}}=2.0 \times 10^{-3} \mathrm{~s}^{-1}$. 


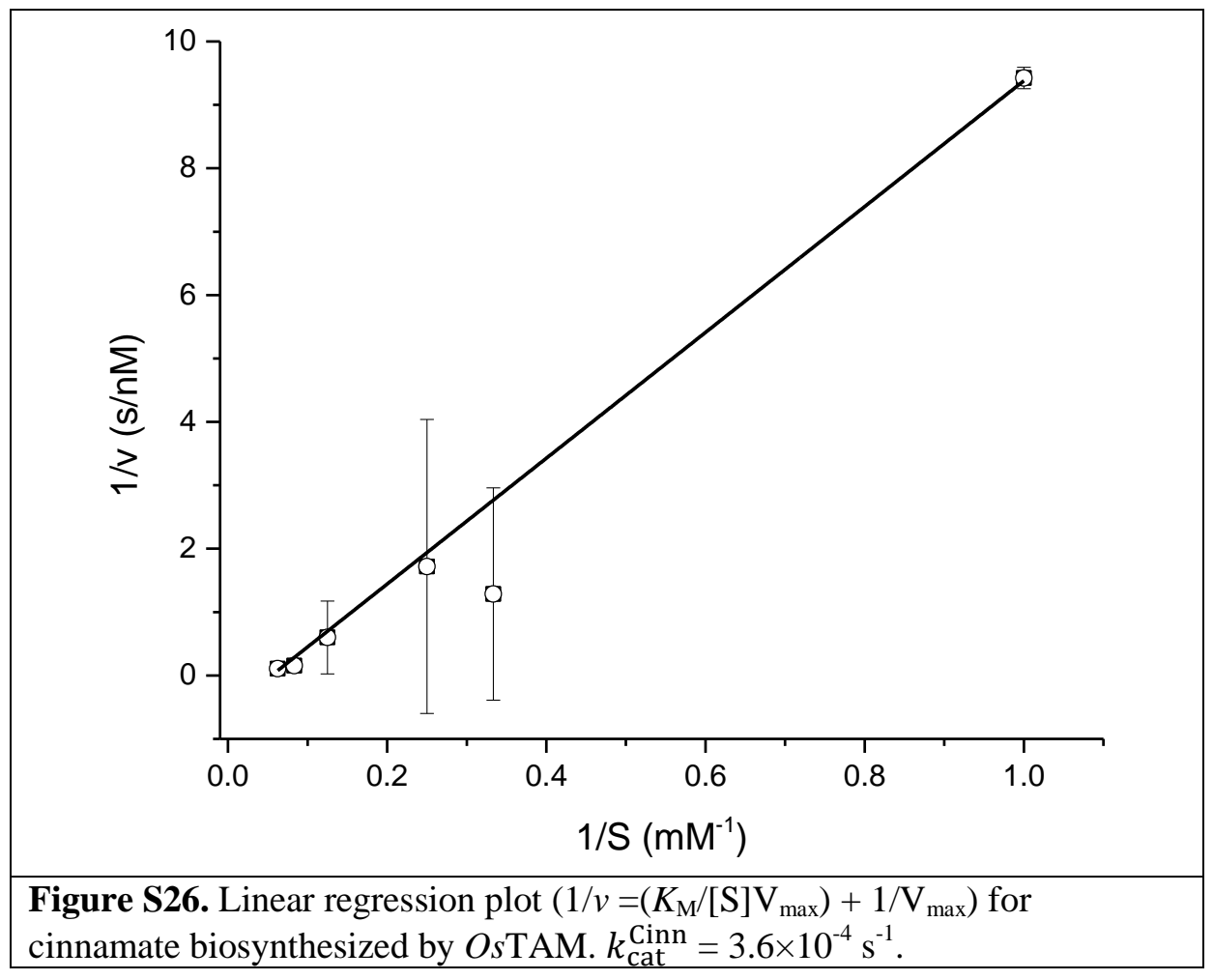

